\title{
Influence of Excitation on Dynamic System Identification for a Multi-Span Reinforced Concrete Bridge
}

\author{
M. Alwash, B. F. Sparling, and L. D. Wegner \\ Department of Civil and Geological Engineering, University of Saskatchewan, 57 Campus Drive, Saskatoon, SK, Canada S7N 5A9 \\ Correspondence should be addressed to B. F. Sparling, bruce.sparling@usask.ca
}

Received 2 March 2009; Revised 11 August 2009; Accepted 28 August 2009

Recommended by Amr Elnashai

In vibration-based damage detection, changes to structural modal properties are tracked over time in order to infer the current state of damage or deterioration. As such, the ability to obtain reliable estimates of modal parameters, particularly natural frequencies and mode shapes, is of critical importance. In the present study, the influence of the dynamic excitation source on the accuracy and statistical uncertainty of modal property estimates for a three span reinforced concrete bridge was investigated experimentally and numerically. Comparisons were made between the dynamic responses due to vehicle loading, harmonic and random forcing, impact, and environmental excitation. It was demonstrated that natural frequencies and mode shapes extracted from the free vibration response following vehicle and random loading events were of higher quality than corresponding values determined during the forcing phase of those events. Harmonic excitation at resonant frequencies and impact were also found to produce statistically reliable results.

Copyright (C) 2009 M. Alwash et al. This is an open access article distributed under the Creative Commons Attribution License, which permits unrestricted use, distribution, and reproduction in any medium, provided the original work is properly cited.

\section{Introduction}

With advances in high-speed data acquisition technology and dynamic system identification techniques, vibrationbased assessment has emerged as a viable option for monitoring civil infrastructure. Information embedded in vibration signatures reflects a wide variety of structural characteristics, making it possible to evaluate many different aspects of the structural condition with relatively few sensors. The global nature of the dynamic response, coupled with the relative ease with which it can be measured and analysed, makes vibration-based assessment an attractive complement to traditional visual inspection and nondestructive evaluation methods.

Vibration-based damage detection (VBDD) has been identified as one application of vibration monitoring offering great potential benefits for infrastructure management. In this approach, observed changes in the dynamic properties of a structure over time are used to infer the presence and nature of damage or deterioration. As summarised in Doebling et al. [1,2] and Sohn et al. [3], proposed VBDD methods include those based on shifts in natural frequencies [4-6], changes in mode shapes $[7,8]$ or mode shape curvature $[9,10]$, measured differences in flexibility or stiffness [11, 12], changes to modal strain energy [13, 14], and numerical model updating $[15,16]$. Regardless of the specific parameter considered, though, VBDD techniques inevitably require accurate and reliable estimates of vibration mode characteristics.

In classical modal analysis [17], dynamic system identification has traditionally been performed in the frequency domain using frequency response functions (FRFs) that define the causal relationship between measured system inputs (forcing) and outputs (response), thereby providing an unambiguous description of vibration mode properties (natural frequencies, unit-mass normalized mode shapes, and damping). Since this implies controlled or directly measurable forcing, only a limited number of practical options are available for classical bridge testing, including shakers [18, 19], impact loading [20], step-relaxation [21], and instrumented test vehicles [22], all of which require specialized equipment. In addition, to minimise interference from extraneous sources of excitation, measuredforce testing typically necessitates full or partial bridge closure, creating operational difficulties on heavily travelled routes. 
Naturally occurring excitation from unregulated traffic, wind, flowing water, or ground-transmitted vibrations offers a less expensive and intrusive alternative. Since sufficiently detailed measurements of such forces are generally not feasible, however, modal properties must then be estimated using output-only system identification methods [23]. To overcome the resulting lack of specific information, natural bridge excitation is often assumed to resemble a stationary random process featuring a uniform spectrum (i.e., white noise); as such, peaks in the response (output) spectrum are taken to indicate resonant behaviour from which, in a conceptual sense, modal properties can be determined. Difficulties arise, though, due to the presence of persistent harmonic forcing components that are also manifested as peaks in the response spectrum. Also, while it is reasonable to expect the random natural excitation to produce a smooth spectrum in an averaged sense, spectra from specific, finite duration loading events may exhibit significant variation. In either case, it can be difficult to distinguish between forcerelated and resonant response spectrum peaks, introducing the possibility for the misidentification of natural frequencies as well as of operational deflected shapes that differ from pure modes.

As part of a broader research program in structural health monitoring and vibration-based damage detection for bridges, the current study was undertaken to investigate the influence of the dynamic excitation source on the quality and reliability of measured modal properties for a concrete slabon-girder bridge. Using a combination of field measurements and numerical modelling, a variety of dynamic forcing types were considered, including truck, wind, and impact loading, as well as controlled random and harmonic forcing. In all cases, natural frequencies and mode shapes were estimated using output-only system identification, performed either in the frequency or time domain.

\section{Dynamic Loading of Bridges}

Until quite recently, research in bridge dynamics was largely focussed on defining dynamic amplification effects for the purpose of structural design [25-29]. Factors found to influence the intensity of the dynamic response include the ratios of vehicle and bridge natural frequencies and weights, vehicle traverse times relative to the fundamental bridge period, axle spacing, suspension characteristics, and bridge bearing constraints. Roadway imperfections, particularly pronounced irregularities in approaches and at expansion joints, were also identified as important contributors to dynamic excitation.

Dynamic vehicle-bridge interaction was studied by [22] using an instrumented five-axle semitrailer test truck. In total, twelve vehicle vibration modes were observed, with the lowest modes featuring rolling or twisting about the longitudinal truck axis, the mid-frequency modes corresponding to body "bounce" (uniform vertical motion) or pitch (rotation about a transverse axis), and the high frequency modes characterized by "axle hop," the predominantly independent vibration of one axle or two adjacent axles. Vehicle/bridge coupling was observed when the "body bounce" truck frequencies (approximately $1.5 \mathrm{~Hz}$ for air spring suspension and 2.5-3.0 Hz for steel leaf suspension) coincided with the lowest flexural frequency of the bridge, resulting in a slight decrease $(0.05-0.13 \mathrm{~Hz})$ in the corresponding frequency of the vehicle-bridge system. Frequency matching was also found to cause large increases in dynamic "axle hop" forces exerted by vehicles with soft suspensions crossing stiff, shortspan bridges [30]. Numerical methods for modelling vehiclebridge interaction effects have been proposed by several authors $[20,30,31]$.

When dynamic interaction effects are negligible, the vehicle and bridge subsystems can be effectively decoupled. In that case, dynamic contact forces exerted on the bridge by passing vehicles are determined solely by the road surface roughness profile, which is largely random, the mechanical properties (mass, stiffness and damping) of the vehicle, and the travelling speed $[32,33]$. The quasi-static gravitational component of the wheel loads, though, will be identical for all points along the driving path, except for the time lag required for the truck to travel from one point to another. This delayed loading sequence introduces a degree of spatial correlation into the overall traffic loading history of the bridge, even though the arrival of individual vehicles on the bridge may follow a random pattern [34].

Various mechanical devices are also available to excite a structure for the purpose of dynamic testing. Among these, the dynamic exciter or shaker is perhaps the most widely used, in part because it provides the flexibility of being able to generate different forms of dynamic excitation time histories, including sinusoidal, random, or chirp. Mechanical shakers make use of a rotating eccentric mass to generate the prescribed forcing; due to the physical constraints involved in such a system, though, the magnitude and form of the resulting force is somewhat limited. More flexible in many respects is the electromagnetic shaker, which converts an input electrical signal into an alternating magnetic field that drives the shaker. Shakers making use of hydraulic actuators as the driving mechanism, though, offer the potential advantage of incorporating long stroke lengths, thereby enabling larger amplitude motion at the low frequencies that are of interest for bridges [17].

As a convenient alternative, impact excitation offers the advantages of low cost, simplicity and speed of execution. In addition, controlled impact produces a broadband form of excitation that imparts a fairly uniform energy level over a predetermined frequency range $[18,35]$. The impact equipment typically consists of an impactor, usually with tips of varying stiffness to control its dynamic range, and an attached load cell used to measure the impulse transmitted to the test structure. The impactor can take the form of a hammer that can be operated by hand, a drop weight mechanism, or spring loaded device [17]. Experimental setup and signal processing requirements associated with impact testing are detailed in [36, 37].

Step relaxation is generally considered to be suitable for large-scale structures that are difficult to excite using other means. In this approach, a steady load applied to the structure by means of a pretensioned steel cable or rope is suddenly released, inducing free vibration [21]. 


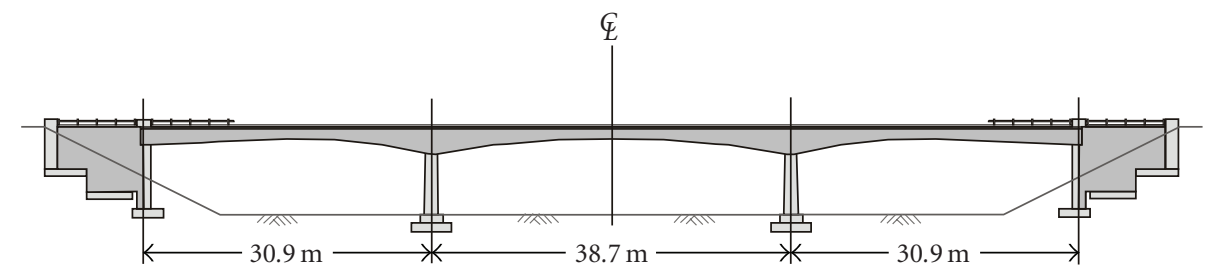

(a)

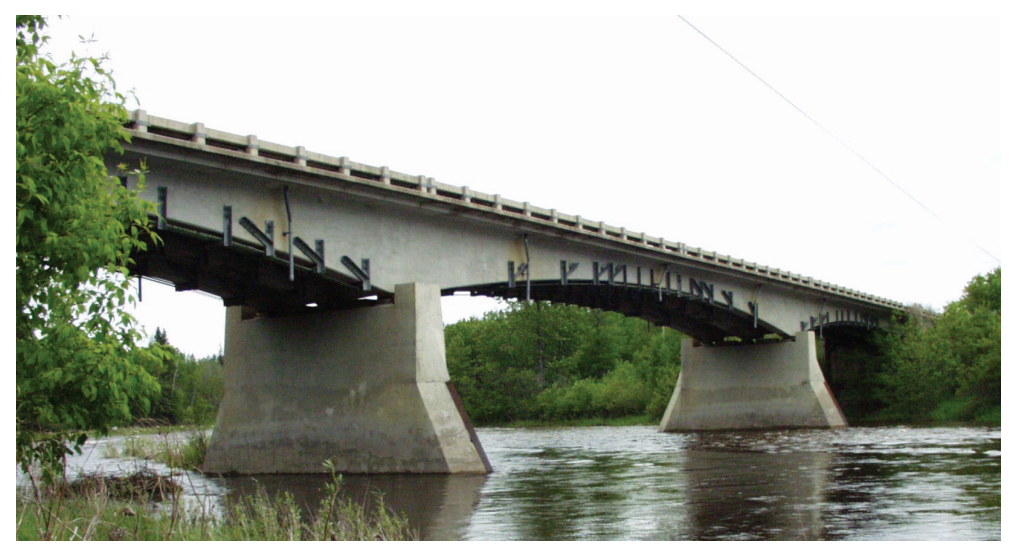

(b)

FIGURE 1: Red Deer River Bridge: (a) bridge elevation and (b) photograph showing external reinforcement prior to 2007 rehabilitation.

In a review of various ambient and controlled input excitation methods, Farrar et al. [38] concluded that there was a lack of consensus on the most appropriate approach for bridge testing, although ambient testing was identified as being the most practical. Zhang [39] reported that the modal data obtained from impact tests were of lower quality compared to those obtained using forced vibration. Similarly, in a comparison of shaker excitation using a sine-sweep signal, vehicle induced response, and hammer impact, Brownjohn et al. [40] found that the shaker excitation yielded the most reliable dynamic data. Studying the variability in modal parameters related to the excitation source, Farrar et al. [18] determined that natural frequencies extracted from impact hammer test data were more statistically reliable than those obtained using ambient excitation, and that fewer vibration modes could be successfully identified from ambient testing. On the other hand, Peeters and De Roeck [23] reported that ambient excitation was found to yield comparable results to those obtained using either a band-limited shaker or dropweight impact.

\section{Field Testing Program}

3.1. Description of Bridge. The bridge under investigation spans the Red Deer River on Provincial Highway No. 9, South of Hudson Bay, Saskatchewan, Canada. Built in 1957, the $100.5 \mathrm{~m}$ long continuous reinforced concrete bridge features three spans, each of which is supported by three arched concrete girders (Figure 1). The bridge was strengthened in 1989 by adding external steel reinforcement to regions of high positive moment, as shown in Figure 1(b); at the same time, additional negative moment reinforcing was included as part of the deck rehabilitation [41]. In 2007, the external reinforcement within the central span was replaced by steel plates attached to the girder soffits to provide additional flexural capacity.

In the context of this study, it should be noted that the Red Deer River Bridge is located in a remote area with limited traffic volumes. As a result, the vehicle loading experienced by the bridge during the test period was sporadic, generally consisting of isolated trucks or passenger vehicles. Although these traffic patterns facilitated the study of vibrations due to single vehicles and ambient (wind- and water-induced) sources, it was not possible to obtain sufficient data on the response to a continuous stream of unregulated traffic. Similar traffic conditions are typical for many of the bridge structures located on the rural highway network throughout Saskatchewan.

3.2. Description of Field Testing Program. A field testing program was undertaken to evaluate the influence of dynamic forcing characteristics on measured modal properties as well as to provide a realistic basis for calibrating the finite element model used in this study. The bridge response was monitored using accelerometers and strain gauges under controlled static and dynamic truck loading, unregulated traffic conditions, and environmental (wind and flowing water) excitation.

Acceleration time histories were recorded using a total of seven accelerometers installed temporarily at 13 locations within the central span of the bridge; due to the limited number of available sensors and the restricted periods of 


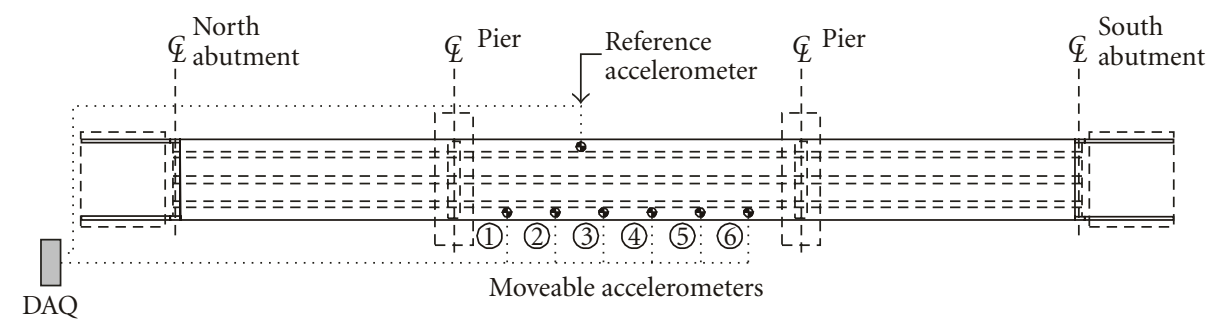

- Accelerometer

FIGURE 2: Plan view of bridge showing accelerometer layout (shown with west side instrumented).

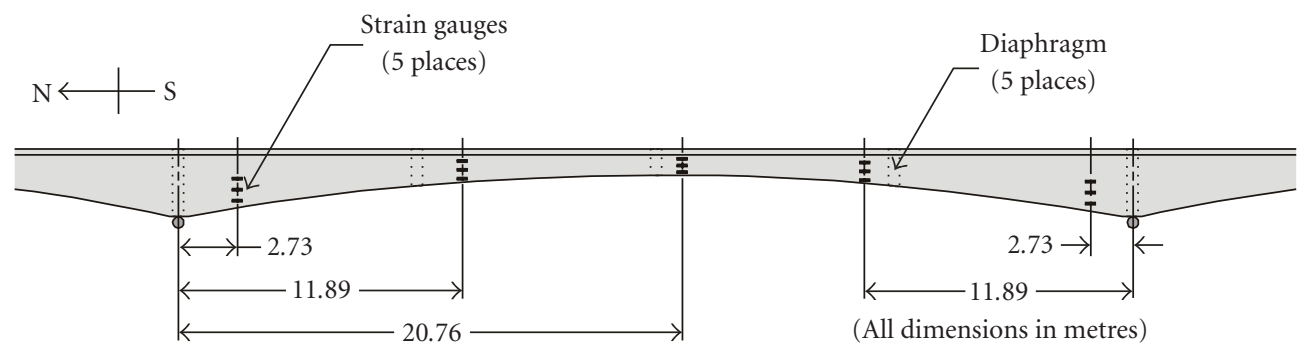

Figure 3: Elevation of central span showing strain gauge locations [24].

access on the bridge, the exterior spans were not monitored. The six moveable sensors and one fixed reference sensor were positioned as shown on Figure 2, with locations chosen to avoid nodal points (points of zero response) on the first several vibration mode shapes; the accelerometers were attached using anchor bolts drilled into the upper surface of the concrete sidewalks adjacent to the railing on both sides of the bridge. Only one side of the bridge was instrumented at a time, with the same layout adopted for the six moveable accelerometers when placed along either the east or west side of the bridge. The reference accelerometer remained at the same location throughout to provide a common datum for scaling readings from both sides of the bridge. In this way, the various measurements could be "glued" together to model the response of the whole bridge [40, 42]. EpiSensor FBA ES-U accelerometers, manufactured by Kinemetrics Inc., were used, configured for a maximum range of $\pm 0.25 \mathrm{~g}$ and precision of $7.6 \mu \mathrm{g}$. All accelerometer data was acquired at a sampling rate of $300 \mathrm{~Hz}$.

A peak-picking technique was employed to estimate modal parameters (natural frequencies and vibration mode shapes) using response spectra obtained from a Fast Fourier Transform (FFT) of the measured acceleration time histories. Prior to performing the FFT, the mean (DC) component of the accelerometer record was removed and an appropriate window function applied to reduce leakage in the resulting spectra; an exponential window function was selected for the decaying free vibration response caused by truck loading events [36], while a Hanning function was used for the forced vibration phase of traffic loading events as well as for ambient vibration measurements [43]. To attenuate the influence of random components in the response, crosspower spectra $\left(G_{x y}(f)\right)$ relating the readings of a given accelerometer with those of the reference sensor were used as the basis for modal identification [18, 29]. In addition, singular-value decomposition of the cross-spectral matrix was used to assist in the peak-picking process [23, 44]. Although the stochastic subspace identification (SSI) modal analysis method described in Section 4.2 was also applied to the measured data, the peak-picking approach appeared to provide slightly more consistent results for the field component of the study.

The central span was also instrumented with 45 electrical resistance strain gauges, with groups of three gauges aligned vertically at five locations along each of the three girders (Figure 3), facilitating the estimation of local girder curvatures. Designed specifically for strain measurements on concrete surfaces, the $120 \Omega$ WFLM-60-11-2LT gauges (TML Co.) were $60 \mathrm{~mm}$ in length, with $90 \mathrm{~mm}$ long backing, allowing them to span multiple microcracks and provide a reasonable indication of the average surface strain. In this study, measured strains were used only for the purpose of verifying the calibrated finite element models results, as described in Section 4.1. However, dynamic strain readings were also utilized in a companion study [24] to estimate various design-related parameters such as peak transient bending moments, dynamic amplification effects, and girder load-sharing characteristics.

Data were acquired using a 16-bit data acquisition system (DAQ) consisting of a PCMCIA card (Model NI DAQCard6036E) and a model SCXI-1001 data acquisition chassis from National Instruments, along with several modules used to acquire and modulate sensor signals. The data acquisition 

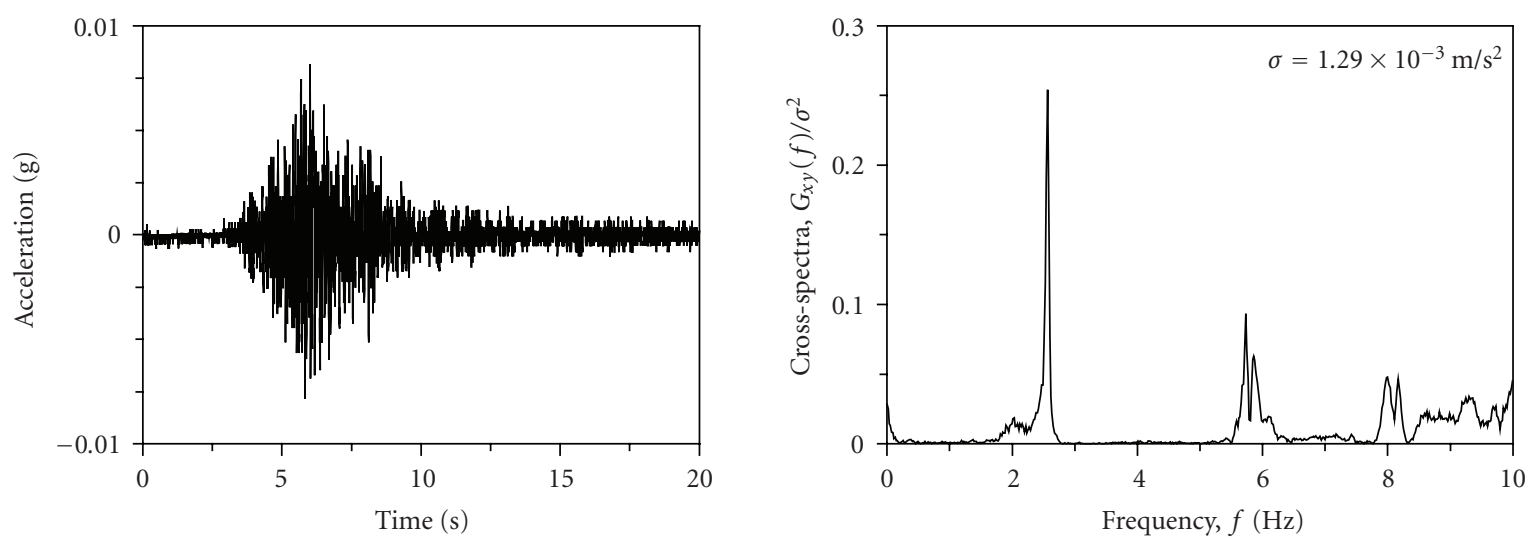

(a)
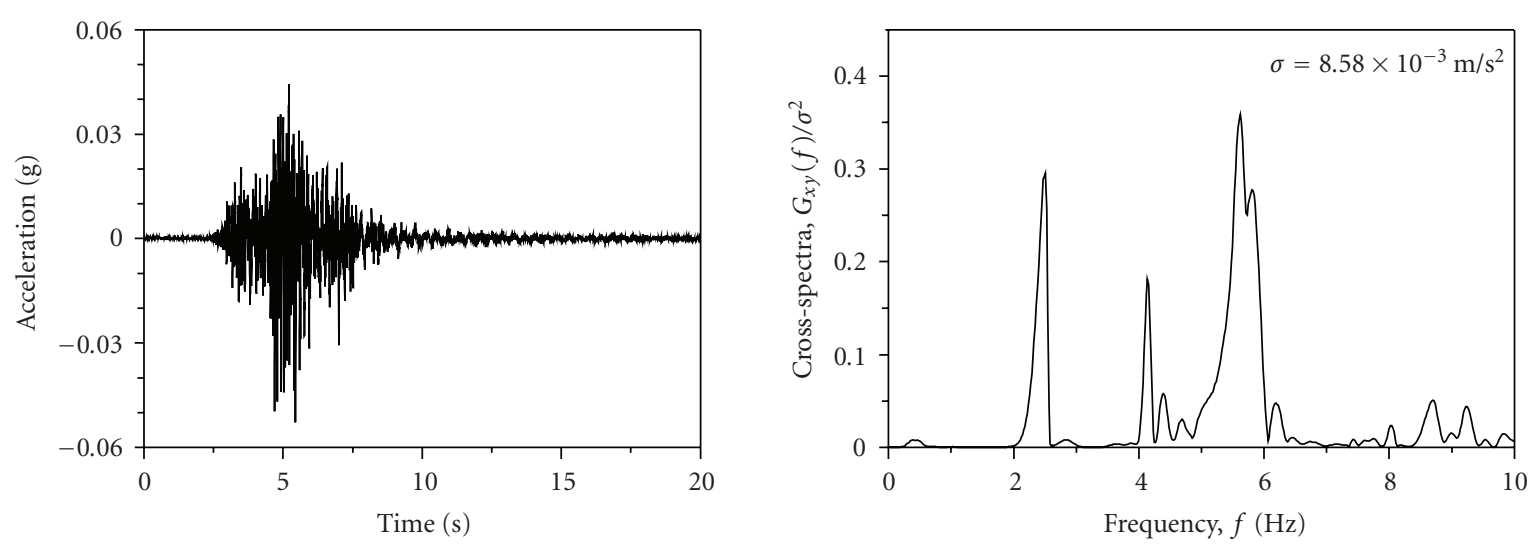

(b)
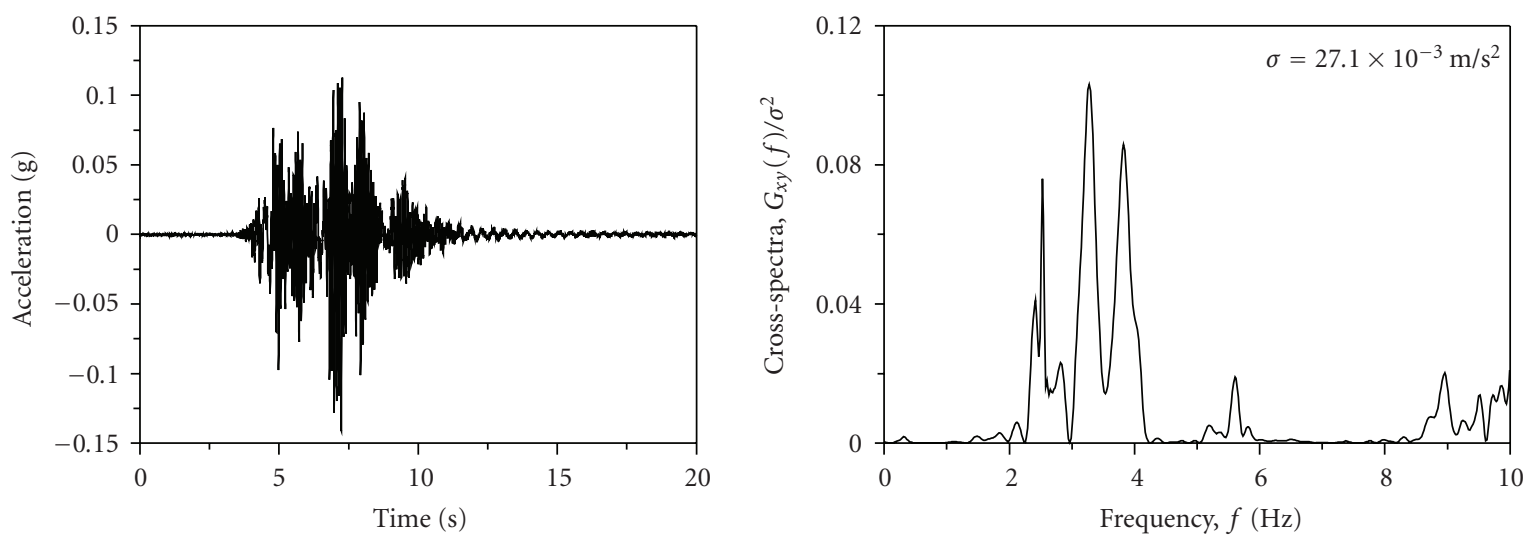

(c)

Figure 4: Typical measured acceleration time histories and normalized cross-spectra for entire unregulated truck loading events: (a) small passenger truck, (b) 20 tonne truck, and (c) 65 tonne truck.

system was controlled by LabView software installed on a notebook computer.

3.3. Measured Response Characteristics. For truck-induced vibrations, each excitation event was analysed in two stages. First, the entire time history of the individual loading event was considered, starting from the instant that the truck first entered the bridge. Subsequently, the decaying free vibration segment of the response time history (after the truck had left the bridge) was isolated and analysed separately. In this manner, the forced and free vibration response characteristics associated with the same loading event could be compared. A variety of trucks with differing weights and configurations were observed; although velocities were not measured or estimated for individual events, typical vehicle speeds were thought to range between 70 and $100 \mathrm{~km} / \mathrm{hr}$. 
Typical acceleration time histories, along with corresponding cross-power spectra $G_{x y}(f)$, as described in Section 3.2, are shown in Figure 4 for three unregulated truck loading events of varying intensities: a passenger truck (approximately 2 tonnes) event recorded at moveable sensor location no. 3 on the east side of the bridge (see Figure 2), a semitrailer truck (approximately 20 tonnes) event recorded at moveable sensor location no. 2 on the east side of the bridge, and a timber truck (approximately 65 tonnes) event recorded at moveable sensor location no. 1 on the west side of the bridge. Here, and in subsequent plots, the cross-spectra have been normalized by the mean-square value $\sigma^{2}$ of the measured acceleration for the event; corresponding root-mean-square values $\sigma$ have been included on the plots.

One characteristic feature of the isolated truck loading events was their limited duration, with the strong motion lasting four to six seconds. Strictly speaking, therefore, the transient nature of these response histories violates the assumption of stationary behaviour implicit in many outputonly modal analysis methods. Furthermore, the frequency content of the response to individual events of a similar nature was found to exhibit little commonality, with the exception of a fairly persistent peak near the fundamental natural frequency at $2.5 \mathrm{~Hz}$. Instead, the response spectra appeared to be strongly influenced by the characteristics of the particular forcing event. As a result, reliable mode shape estimates could not be generated from the forced response phase of truck loading events based on the limited number of events recorded in this study.

The acceleration response for the free vibration phase (after the truck had left the bridge) of the same three events is summarised in Figure 5; due to the predominance of the response at the fundamental natural frequency, effectively obscuring peaks at other frequencies, a second plot has been superimposed on the cross-spectra in which response components at higher frequencies have been amplified by the specified factor. In the free vibration phase, clear modal response peaks could be easily and unambiguously identified at the three lowest natural frequencies of the bridge $(\approx 2.5 \mathrm{~Hz}$, $4.2 \mathrm{~Hz}$, and $5.7 \mathrm{~Hz}$ ) from the cross-spectra of isolated events. It is interesting to note, though, that higher mode response was relatively less prominent for the 65 tonne truck event (Figure 5(c)) than for the 20 tonne event (Figure 5(b)), despite the increased loading intensity for the larger truck. This clearly demonstrates the importance of factors such as vehicle speed, axle configuration, weight distribution, suspension characteristics, and driving path roughness in determining a truck's effectiveness in exciting specific modes. For the passenger truck loading event (Figure 5(a)), higher mode responses were more difficult to distinguish confidently due, in large part, to the lower measurement signalto-noise ratio that was a characteristic of small vehicle events; this higher relative noise level is evident in the enhanced wide-band high frequency content (say, above $4 \mathrm{~Hz}$ ) of the cross-spectrum in Figure 5(a), as compared to that in Figures 5(b) and 5(c). Statistical properties of natural frequencies and mode shapes extracted from truck-induced free vibration are reported in the following section.
Ambient vibrations due to wind and flowing water were also recorded without traffic on the bridge; the results presented here were obtained during a period of fairly brisk winds and high river flows. A typical cross-spectrum for a single 30 second ambient acceleration record is presented in Figure 6(a), clearly exhibiting the broad-band nature of the random fluctuations associated with this type of excitation. As may be expected, modal participation in the observed vibrations for any given sampling period varied according to the frequency content and spatial organization of the wind gusts interacting with the bridge over that period. For this particular data set, resonant response at the fundamental natural frequency $(\approx 2.5 \mathrm{~Hz})$ could not be distinguished from background (quasistatic) vibrations, while higher modal responses could be identified at $4.2 \mathrm{~Hz}, 5.7 \mathrm{~Hz}$, and $8.2 \mathrm{~Hz}$, although nonresonant peaks are present in this region as well.

Random variations in the response spectra could be attenuated significantly by averaging results obtained from multiple data segments [43]. For example, Figure 6(b) shows an averaged cross-spectrum derived from a 140-second acceleration record that has been subdivided into 30 second segments, defined such that the segments overlapped in time by $60 \%$.

In this averaged cross-spectrum, resonant responses in the lowest four modes can be readily differentiated from the background vibrations. Comparing this still rather "noisy" averaged ambient vibration spectrum with that obtained during the free-vibration phase of truck loading (Figure 5), however, it is evident that further averaging using longer ambient measurement periods would be required to produce comparable levels of reliability in modal identification.

3.4. Measured Modal Parameters. To obtain some sense of the statistical characteristics associated with measured dynamic properties, natural frequencies and mode shapes were estimated from multiple unregulated truck loading events over the course of a single day. A total of 14 events involving heavily loaded timber trucks were recorded, eight of which occurred while the moveable accelerometers were positioned along the east side of the bridge and the remaining six with the accelerometers along the west side. The recorded duration of individual events typically ranged from 20-30 second. Only the free vibration portion of the response to each event was considered for this purpose.

Statistical properties of the measured natural frequencies for the lowest three modes are summarised in Table 1, including observed mean values and coefficients of variation (cov) derived from the six cross-spectra generated in each of the 14 recorded events. It is evident that the natural frequencies could be extracted with a high degree of reliability, with coefficients of variation for the three modes ranging from $0.53 \%$ to $0.65 \%$.

The fundamental mode shape measured along both edges of the central span, as derived from the acceleration cross-spectra described in the previous section, is plotted in Figure 7(a), normalised relative to the reference accelerometer. The same data are replotted in Figure 7(b) including error bars indicating the standard deviations of modal amplitudes observed at each sensor location for all the 

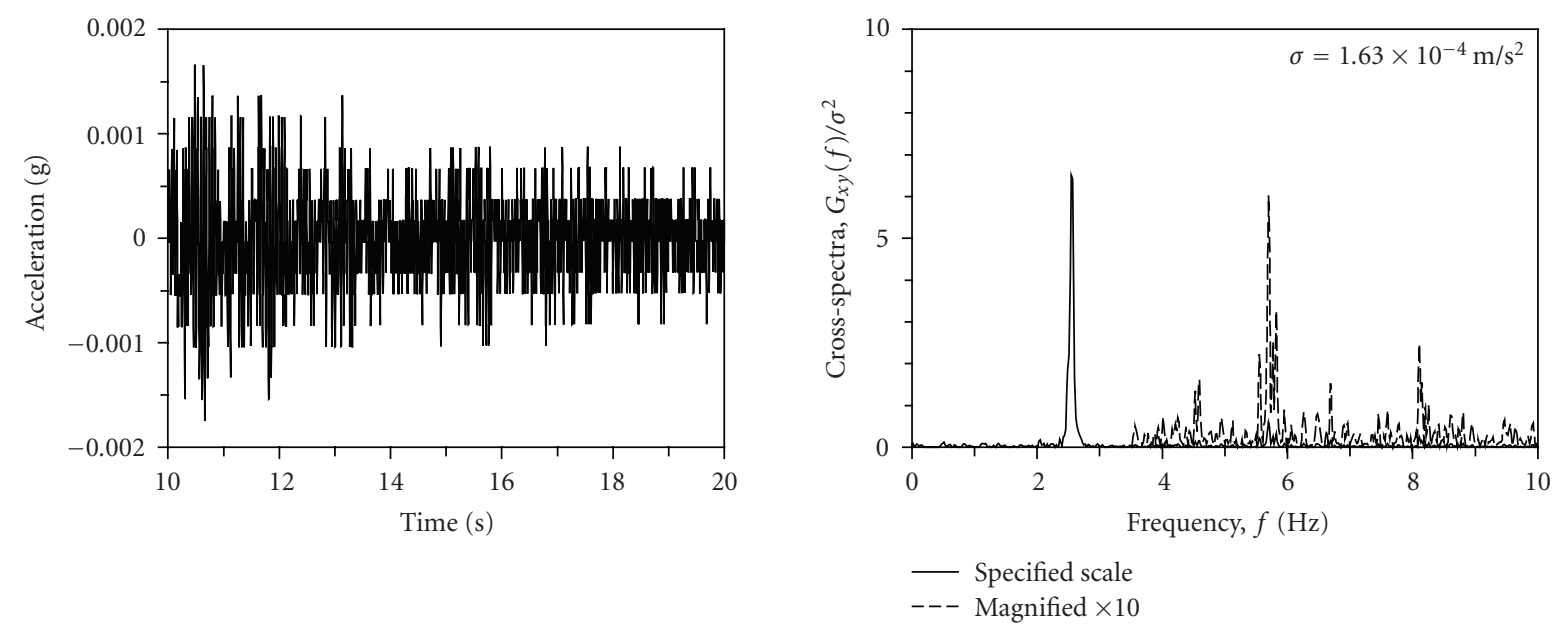

(a)
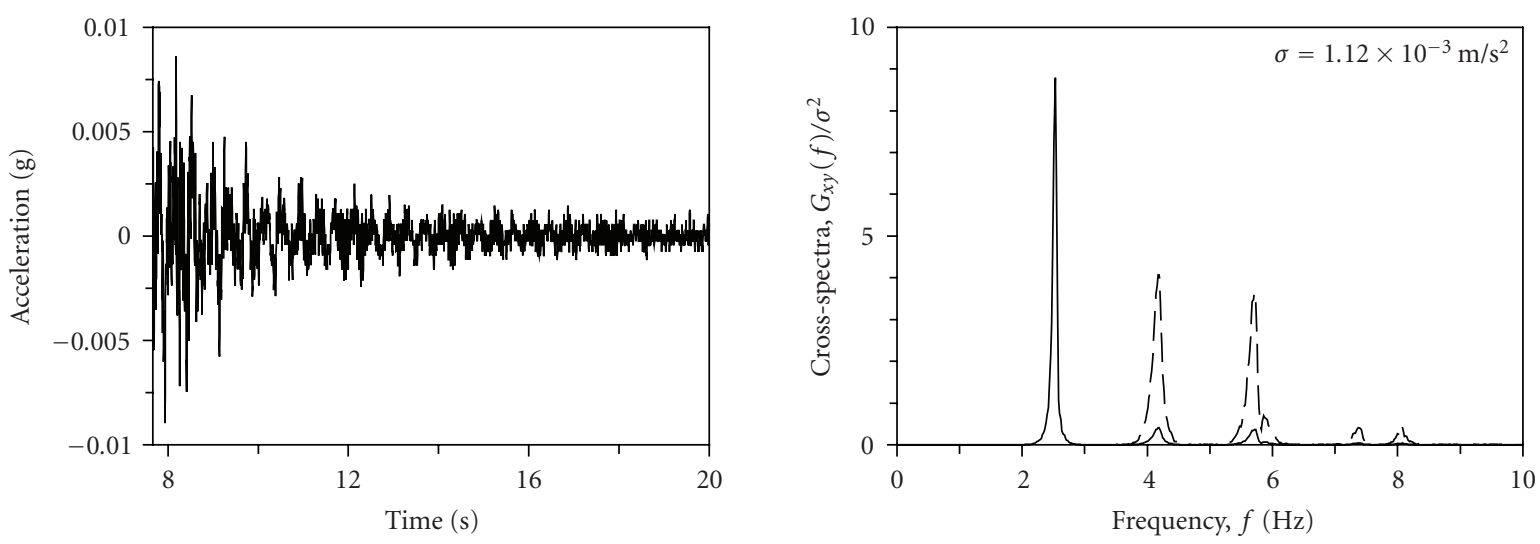

- Specified scale

- - Magnified $\times 10$

(b)
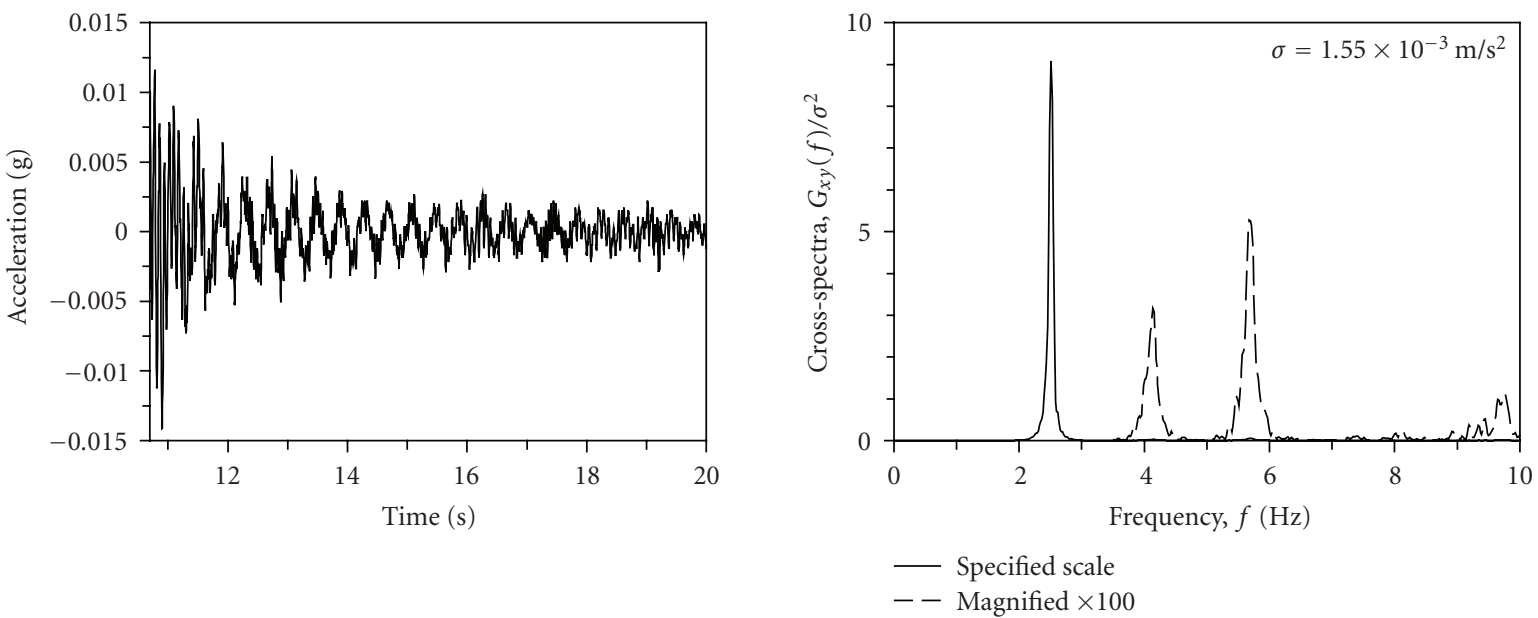

(c) events: (a) small passenger truck, (b) 20 tonne truck, and (c) 65 tonne truck. 


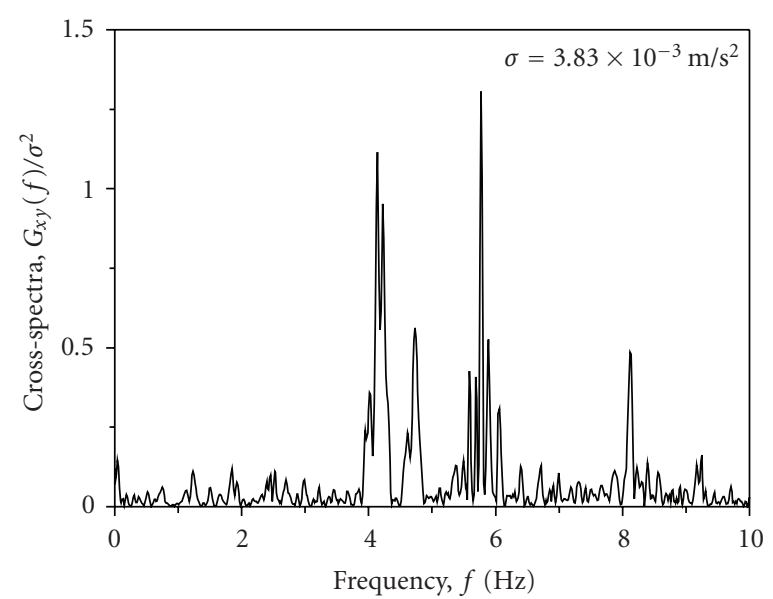

(a)

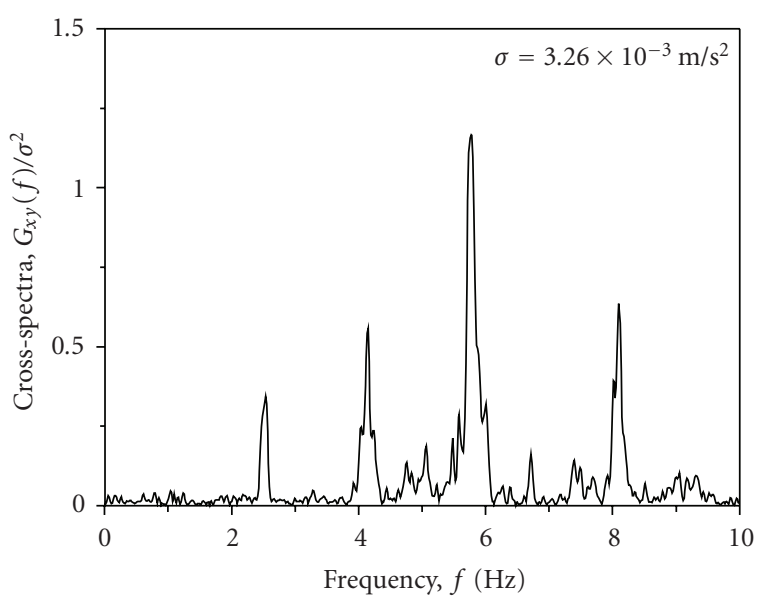

(b)

FIGURE 6: Measured acceleration normalized cross-spectra due to ambient (wind and water) excitation: (a) single 30-second record, and (b) average of overlapping 30-second records over a 140-second period.

TABLE 1: Measured natural frequencies for multiple loading events.

\begin{tabular}{lcc}
\hline Mode & \multicolumn{2}{c}{ Natural frequency } \\
& Mean value $(\mathrm{Hz})$ & Cov $(\%)$ \\
\hline 1 & 2.49 & 0.65 \\
3 & 4.16 & 0.53 \\
\hline
\end{tabular}

recorded events (i.e., eight events for the east side locations, and six for those on the west side). Here, the west side mode shape has been offset vertically for illustrative purposes. The flexural nature of the fundamental mode is apparent, with similar amplitudes seen along both sides of the bridge. The average coefficients of variation in modal amplitudes found along the east and west sides of the bridge were $4.21 \%$ and $4.11 \%$, respectively. Even at this low level of variability, though, a large number of truck loading events would be likely required to define mode shapes with sufficient precision to ensure the successful implementation of VBDD methods for small-scale damage detection [45].

\section{Description of the Numerical Study}

4.1. Finite Element Model Definition and Calibration. To consider additional forms of excitation in a more controlled manner, a detailed linear finite element (FE) model of the Red Deer River Bridge was generated using the commercial analysis program ANSYS [46]. An added benefit of the numerical study was the ability to isolate the consideration of dynamic excitation from the many uncertainties inherent in field testing of large structures.

An accurate geometrical representation of the bridge was assembled using quadratic (20 node) three-dimensional solid elements to model the bridge girders, deck, curbs, and diaphragms (Figure 8); the guardrails were approximated as beam elements connected by rigid links to the curb.
The external steel reinforcement on the bottom face of the girders was modelled using quadratic (8 node) membrane elements whose cross-sectional areas and material properties approximated those of the actual external reinforcement. In total, the model contained 26,036 nodes and 4,126 elements.

The FE model was manually calibrated using a trialand-error adjustment procedure to reproduce the natural frequencies and vibration mode shapes extracted from site measurements. The principal parameters adjusted in the calibration process were the effective modulus of elasticity values for the concrete in the girders and deck, making allowances for the presence of cracking and internal reinforcing steel. In addition, longitudinal and rotation springs were introduced at the bridge pier and abutment support locations in order to properly recreate the partial arching behaviour inferred from measured girder strains; such support restraint may arise, for example, as a result of localised corrosion and/or the accumulation of debris in the bridge bearings over time. Selected material properties for the calibrated finite element model are provided in Table 2. The higher apparent elastic modulus of the concrete in the bridge girders, compared to that of the deck and other components of the bridge, was attributed to the presence of significant compressive axial forces in the girders that would substantially reduce the extent of flexural cracking as well as to higher steel reinforcement ratios; the higher girder values were also consistent with trends observed in nondestructive testing results carried out during the field studies.

In Table 3, comparisons are presented between the lowest three natural frequencies of the bridge extracted from the measured data and those calculated from the calibrated FE model. It is evident that the observed agreement was excellent for all three natural frequencies $(0.2 \%, 3.3 \%$, and $0.2 \%$ differences, resp.).

The lowest three bridge vibration modes, as generated from the FE model, are illustrated in Figure 9; all three are seen to be predominately flexural modes, although a torsional fourth mode was identified in close proximity to 


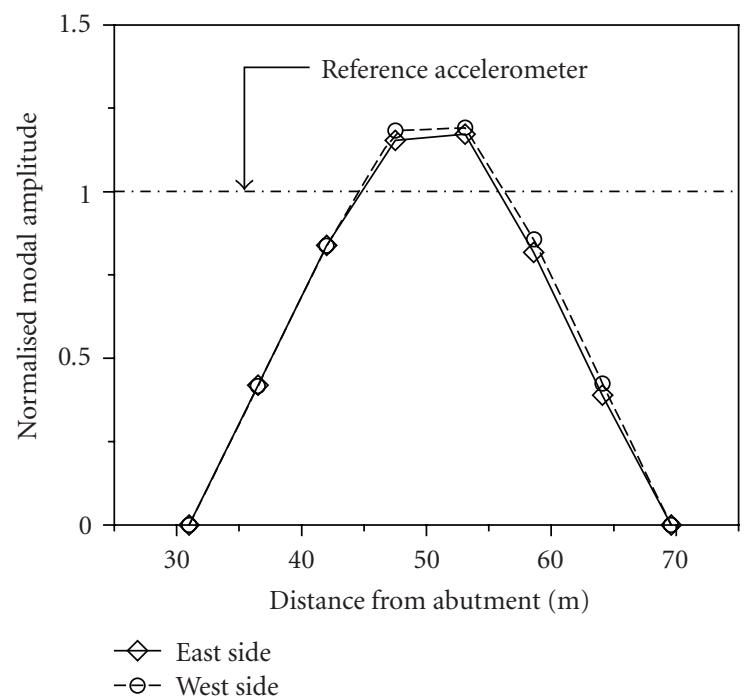

(a)

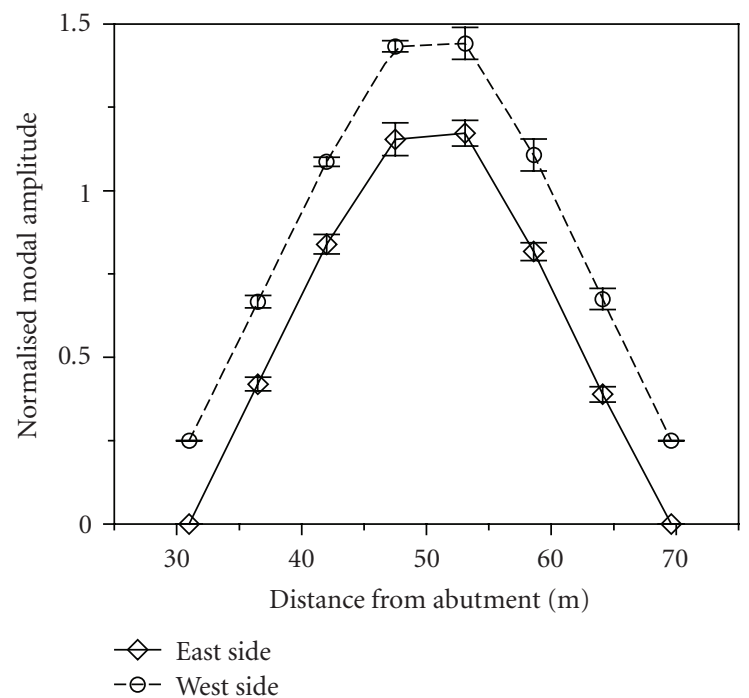

(b)

FIGURE 7: Measured fundamental mode shape over central span: (a) using a common datum for both sides, and (b) showing standard deviations (with west side values offset for clarity).

the third natural frequency $\left(f_{4}=5.88 \mathrm{~Hz}\right)$. As an indication of the level of agreement between the measured and calculated mode shapes, Modal Assurance Criteria (MAC) values for each mode are provided in Table 3 [17]. The MAC measures the least-squares fit between two different mode shapes, with a MAC value of one indicating perfectly consistent modes and a value of zero indicating orthogonality. As shown in Table 3, good agreement was also found between calculated and measured mode shapes, particularly for the fundamental mode (MAC $=0.9988$ ).

Further validation of the calibrated model was provided by comparisons of measured and calculated strains resulting from controlled static load tests, an example of which is presented in Figure 10. At the instant illustrated here, the test truck was travelling north at crawl speed and, assuming that

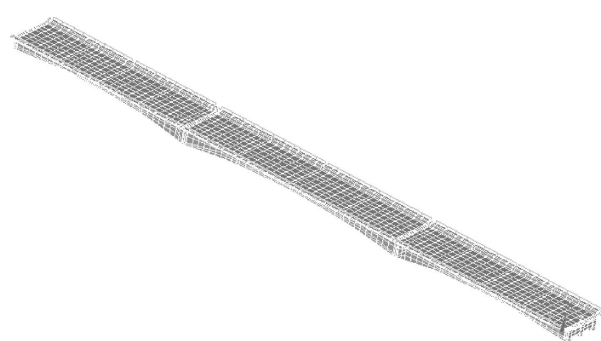

(a)

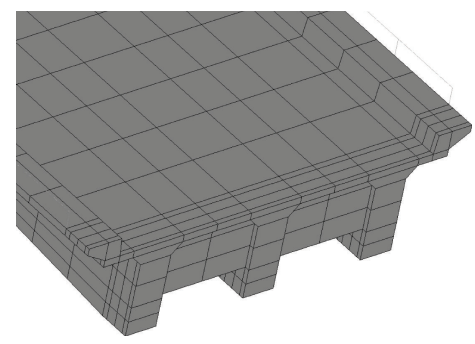

(b)

FIGURE 8: Schematic of the finite element model: (a) isometric view of entire model, and (b) close-up view of south end showing meshing details.

TABLe 2: Selected material properties of calibrated finite element model.

\begin{tabular}{llc}
\hline Material/item & Property & Value \\
\hline \multirow{2}{*}{ Concrete } & $\begin{array}{l}\text { Elastic } \\
\text { modulus-Bridge } \\
\text { girders }\end{array}$ & $35.2 \mathrm{GPa}$ \\
& $\begin{array}{l}\text { Elastic } \\
\text { modulus- } \\
\text { Remaining } \\
\text { components }\end{array}$ & \\
& $\begin{array}{l}\text { Poisson's ratio } \\
\text { Density }\end{array}$ & $25.0 \mathrm{GPa}$ \\
& Elastic modulus & 0.2 \\
Steel & Poisson's ratio & $2,450 \mathrm{~kg} / \mathrm{m} 3$ \\
\hline Density & 0.3 \\
Support springs & $\begin{array}{l}\text { Longitudinal } \\
\text { springs } \\
\text { Rotational } \\
\text { springs }\end{array}$ & $15,850 \mathrm{~kg} / \mathrm{m} 3$ \\
\hline
\end{tabular}

a constant speed was maintained throughout, was judged to have reached the middle of the central span in the east traffic lane; corresponding results from the finite element model were obtained with simulated truck wheel loads applied statically in the same lane with the first tandem axle located exactly at midspan. Strains have been plotted for the lowest of the three gauges at each instrumented location, as defined in Figure 3. Overall, trends in the measured and calculated strains of all three girders matched very well, suggesting, at least, that the load-carrying mechanisms and load-sharing between girders were properly reproduced in the finite element model. 


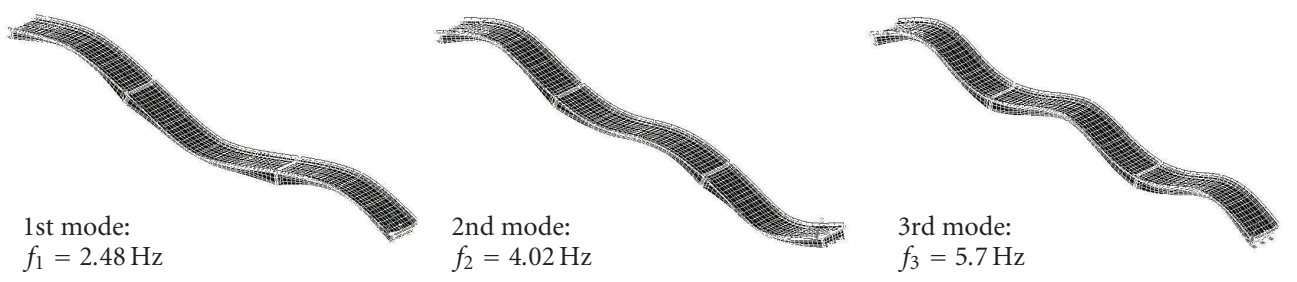

FIGURE 9: Lowest three mode shapes calculated using finite element model.

TABLE 3: Comparison of measured and calculated modal properties.

\begin{tabular}{lcccc}
\hline Mode & Measured & $\begin{array}{c}\text { Natural frequencies (Hz) } \\
\text { Calculated (FE) }\end{array}$ & Difference (\%) & Mode shape: MAC \\
\hline 1 & 2.485 & 2.480 & 0.2 & 0.9988 \\
2 & 4.160 & 4.024 & 3.3 & 0.9594 \\
3 & 5.706 & 5.695 & 0.2 & 0.9425 \\
\hline
\end{tabular}

4.2. Overview of the Dynamic Analysis. The response of the bridge to various forms of dynamic excitation was calculated in the time domain using Newmark's $\beta$ method as the time marching scheme, assuming constant-average acceleration [47]. To reduce computational requirements, the modal superposition approach was adopted, including contributions from the lowest seven vibration modes. Proportional damping equivalent to $2 \%$ of critical was assumed for all modes to reflect the behaviour of lightly cracked reinforced concrete [48]; modal damping ratios in the order of $2 \%$ of critical were also extracted from measured data in the current study, although there was considerable variability in the field results depending, in large part, on the degree to which individual modes were excited by specific loading events.

To simulate the acquisition of data from a limited number of sensors in a field testing program, vertical displacement time histories from 60 selected nodes on the top surface of the deck were extracted and stored for further analysis (Figure 11). The response was calculated at uniform time increments of 0.005 second, simulating a sampling rate of $200 \mathrm{~Hz}$. For impact loading, however, the sampling rate was increased to $2,000 \mathrm{~Hz}$ due to the short duration of the impulse.

Modal properties of the bridge were then estimated from the time domain response at these "sensor" locations, using the stochastic subspace identification (SSI) modal analysis method, as implemented in the commercially available software MACEC [49]. For the purposes of modal parameter estimation, it was assumed that the exciting force was not known, or measured, so that "output-only" modal extraction techniques were required. The extracted modal properties (natural frequencies and mode shapes) were compared to theoretical eigenvalue results generated from the same FE model.

The specific forms of dynamic loading considered in the numerical study included harmonic, random, and impact forced excitation, as well as loading time histories from moving trucks. The first three types of excitation were implemented as a fixed-location vertical force applied at the node in the FE model corresponding to the location of the reference accelerometer in the field measurement study (see Figure 2). Truck excitation, on the other hand, described the moving wheel loads for selected truck configurations as they passed over the bridge at a constant speed. Specific details regarding the various excitation types are presented in more detail below.

\section{Numerical Results}

5.1. Harmonic Loading Excitation. In the numerical study, harmonic loading was used to simulate the excitation induced by a mechanical shaker mounted on the bridge. A harmonic force with an amplitude of $10 \mathrm{kN}$ was applied at frequencies corresponding to the first, second, and third natural frequencies of the bridge.

To evaluate the influence of uncertainty related to the excitation source, the analyses were repeated with random fluctuations (noise) superimposed upon the harmonic load time history. White noise with variances equal to $1 \%, 2 \%$, $5 \%$, and $10 \%$ of that of the original harmonic signal was used. Ten loading events, each with a simulated duration of 10 second, were analysed for all noise levels; the modal properties for each event were extracted, averaged, and then compared to the eigenvalue results. A typical acceleration response spectrum for harmonic loading applied at the lowest natural frequency and containing $2 \%$ superimposed noise is presented in Figure 12(a); data for this, and subsequent, response spectral plots were extracted from the node in the FE model corresponding to the location of the reference accelerometer in the field measurement study (see Figure 2).

Table 4 summarises MAC values for the first mode shape based on a comparison between mode shapes extracted from the time domain analyses with varying levels of uncertainty in the harmonic loading and two different reference mode shapes: one obtained directly from an eigenvalue analysis and the second extracted from the calculated time domain response in which there was no uncertainty (noise) in the definition of the harmonic loading. It is evident that the 


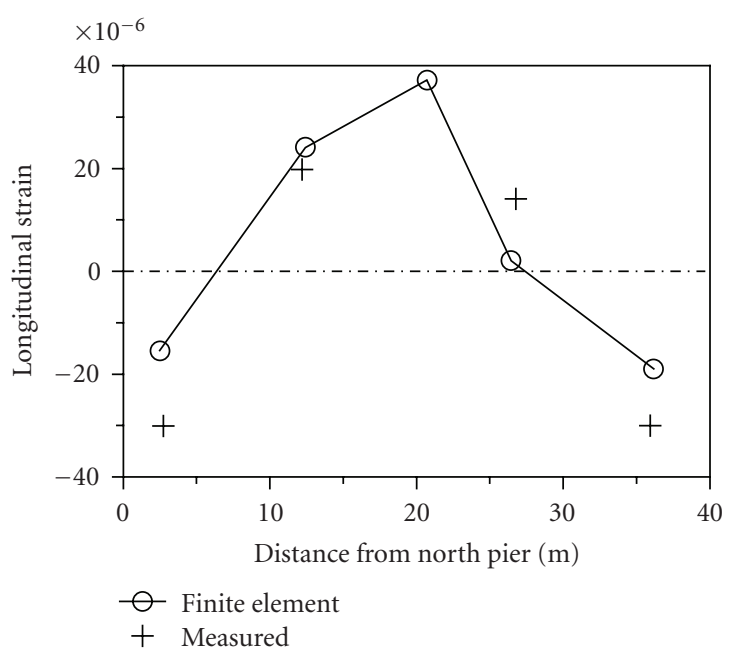

(a)

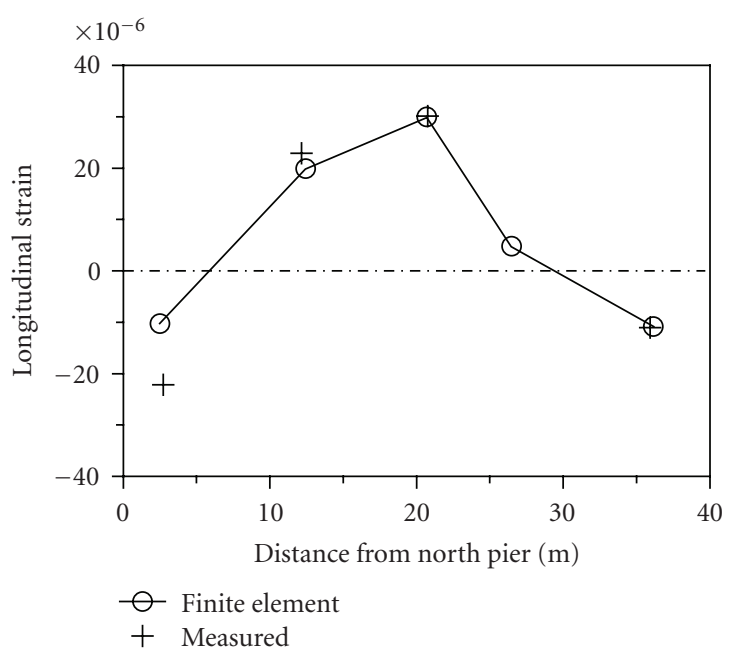

(b)

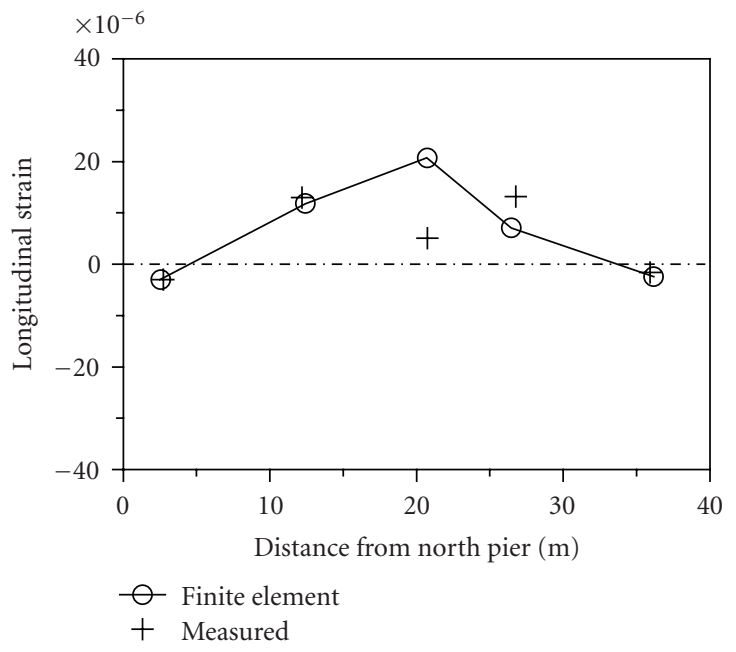

(c)

Figure 10: Comparison of measured and calculated strains near the bottom face of girders in the central span due to a static truck load test: (a) east girder, (b) middle girder, and (c) west girder. level of noise in the harmonic loading had little effect on the reliability of the resulting fundamental mode shapes. This result is not unexpected since the random fluctuations in the superimposed noise were spread uniformly over a wide band of frequencies, meaning that the contribution to the excitation specifically at the fundamental natural frequency was small, despite the relatively large total variance levels in the noise. The consistently higher levels of agreement between the noisy and original time domain response results, as compared to those between the noisy time domain and eigenvalue results, reflects the fact that both the noisy and original time domain results actually represent operational deflected shapes, rather than pure mode shapes, and that both contain similar numerical approximations associated with the selected time marching scheme.

As an additional exercise, numerically generated noise was added to the displacement time histories (output) extracted from the FE analysis to simulate the combined uncertainty associated with various stages within the data acquisition process (i.e., sensor errors, electrical interference, digitizing errors, signal processing, etc.); for this purpose, the forcing function was assumed to be perfectly harmonic (i.e., without noise). The analysis was repeated with random variations of differing magnitudes ( $1 \%$ to $10 \%$ noise) superimposed upon the extracted displacement time histories of each node considered. As indicated in Table 4, the level of noise in the output also had little effect on the reliability of the resulting fundamental mode shape.

For this particular bridge and loading configuration, forced resonant harmonic excitation (with or without noise) did not yield satisfactory definitions of the 2 nd and 3 rd mode shapes, with MAC values of 0.558 and 0.236 , respectively, computed for the extracted modes when compared to corresponding mode shapes derived from the eigenvalue analysis. In addition, modal parameter estimations (using SSI) yielded apparently complex shapes for these modes, indicating that the contributions of the two real-valued modes could not be properly distinguished. These difficulties were attributed to the relatively close proximity of the two natural frequencies $(4.0 \mathrm{~Hz}$ and $5.7 \mathrm{~Hz})$ in question, since an examination of the individual modal response contributions showed that the two modes exhibited roughly comparable magnitudes to harmonic excitation at both the 2nd and 3rd natural frequencies. This suggests that harmonic forcing in the vicinity of two or more closely spaced natural frequencies can produce operational deflected shapes that deviate from pure modes shapes, even when that forcing is applied at one of the resonant frequencies. From the perspective of vibration-based damage detection, the implications of using operational deflected shapes that can be reliably reproduced, but that differ significantly from the desired mode shapes, have not been adequately investigated.

5.2. Random Forced Excitation. Random excitation can be used to excite a bridge over a broad range of frequencies in order to measure the response in several vibration modes simultaneously. In practice, random excitation is typically achieved through the use of wind or unregulated traffic loading. For the numerical study, though, the random forced 


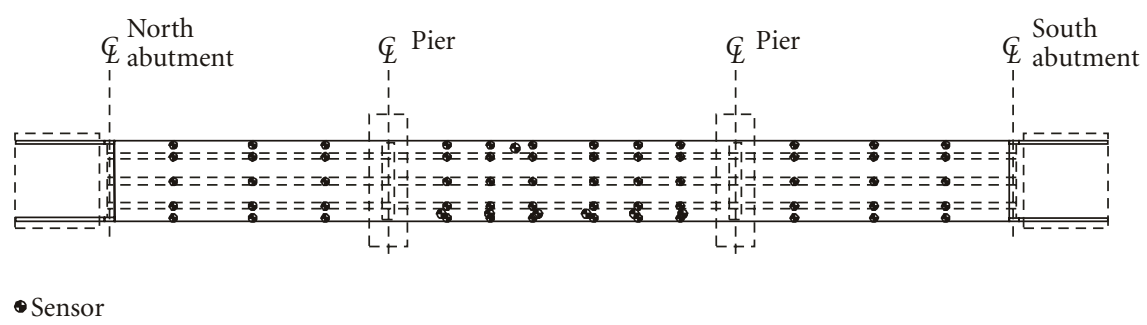

FIgURE 11: Plan view of bridge showing locations of simulated sensor locations for FE study.

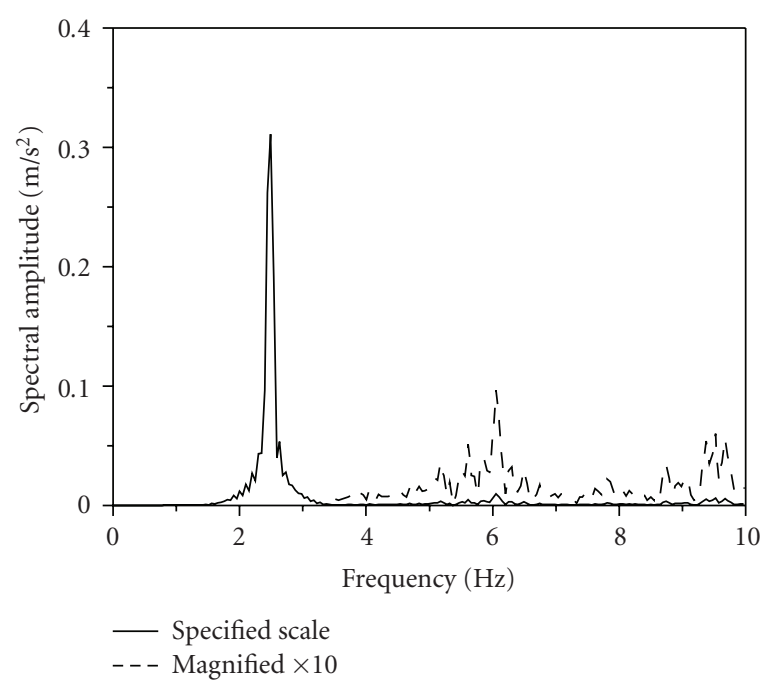

(a)

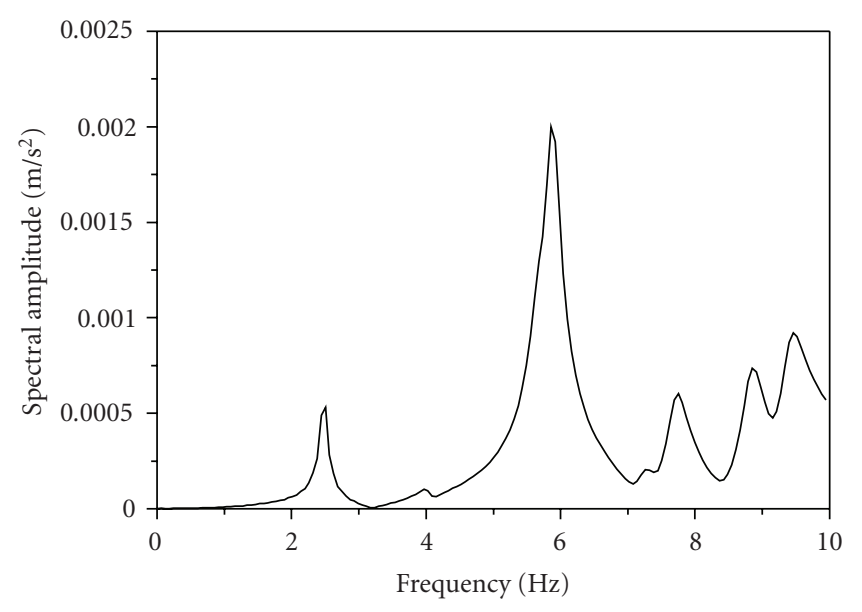

(b)

FIGURE 12: Typical acceleration response spectra from numerical study: (a) harmonic loading at the first natural frequency with $2 \%$ superimposed noise, and (b) impact loading.

excitation was applied as a fixed-location concentrated load with a random time history defined such that the peak magnitude was $10 \mathrm{kN}$ and the resulting force spectrum was approximately uniform over the range of natural frequencies of interest for this bridge.

In total, twenty different random loading events were considered, each comprising a forced excitation phase lasting 10 second, followed by a 5 second free vibration phase during which the forced excitation was discontinued. For the purpose of extracting modal properties, responses in the forced and free vibration phases were considered separately. Typical acceleration response spectra for the forced excitation and free vibration phases of a random load event are shown in Figures 13(a) and 13(b), respectively.

The lowest three natural frequencies extracted from the forced and free vibration phases of the random loading events, averaged over 20 such events, are presented in Table 5; also included are the corresponding standard deviations $(\sigma)$ of the extracted natural frequencies as well as the error in these values relative to the eigenvalue results. From Table 5, it can be seen that the natural frequencies extracted from the free vibration phase were consistently closer to the eigenvalue results. Perhaps more significant from a VBDD perspective, though, is that the standard deviations of the free vibration results were several orders of magnitude lower, indicating that a much more reliable measure of the true natural frequencies was achieved.

MAC values comparing averaged mode shapes derived from the forced and free vibration phases of the twenty random loading events with those from eigenvalue results is presented in Table 6. It is evident that consistently better correlation was achieved using the free vibration data than was obtained from forced vibration, particularly for the higher modes. This result is consistent with observations made based on field measurements of this bridge (Section 3.3).

5.3. Impact Loading Excitation. Simulating the effect of a drop-weight test in the field, excitation from a short duration impulse was used to induce a force exhibiting a flat spectrum over the frequency range of interest. In the present numerical study, the impact load time history was defined as a half sine wave with a duration of 10 milliseconds $[35,37]$ and an amplitude of $10 \mathrm{kN}$ (see Figure 14). The subsequent bridge response was calculated over a 10 second interval. As with the harmonic forcing discussed previously, the effect of random fluctuations in the impact load time history was investigated, but found to have little influence on estimates of either the natural frequencies or mode shapes for the lower modes 


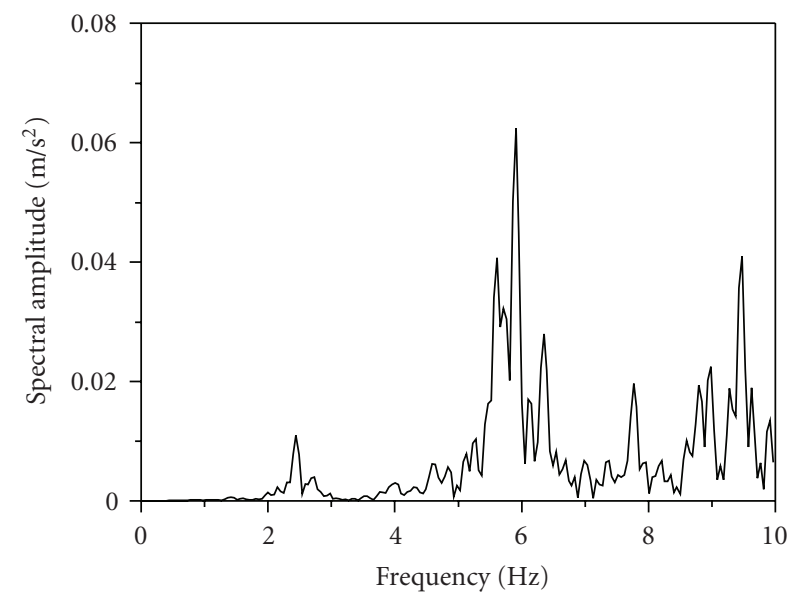

(a)

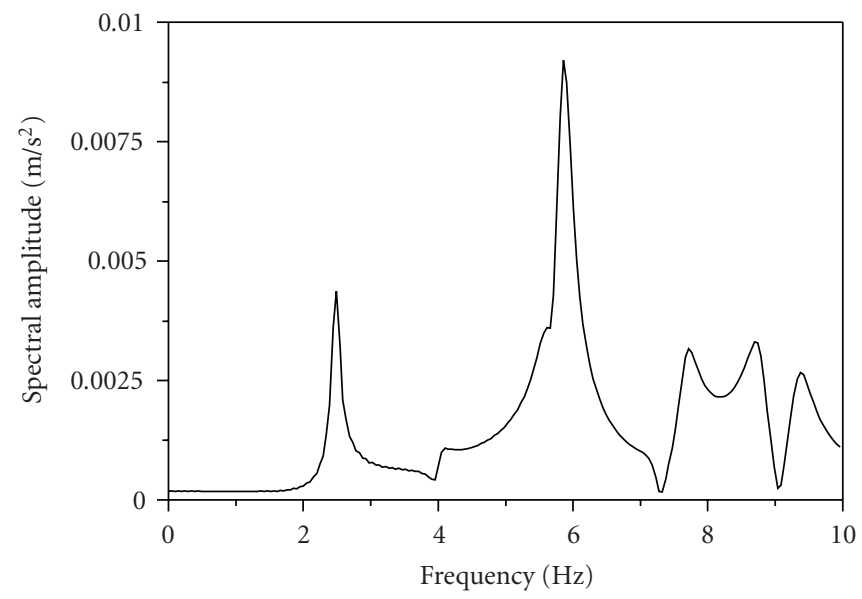

(b)

FIGURE 13: Typical acceleration response spectra from numerical study of random loading: (a) forced excitation phase, and (b) free vibration phase.

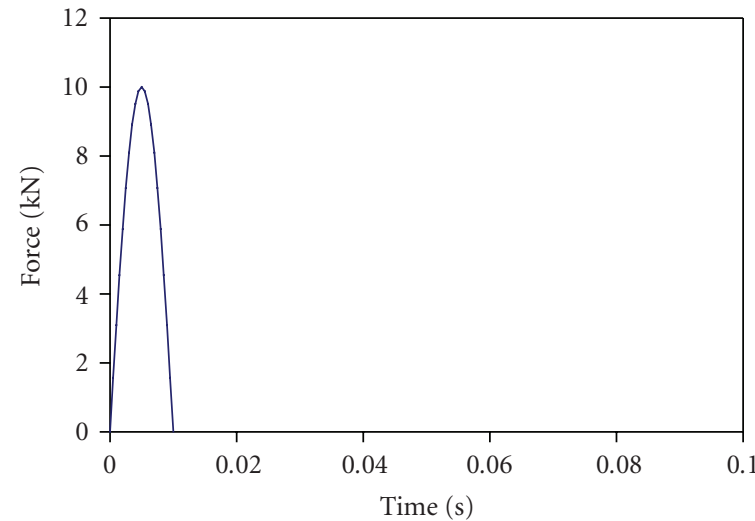

(a)

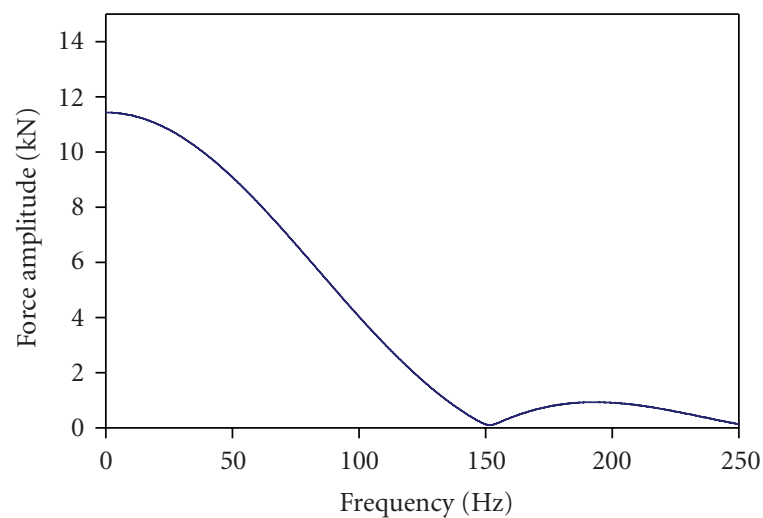

(b)

FIGURE 14: Simulated impact loading: (a) force time history, and (b) force spectrum.

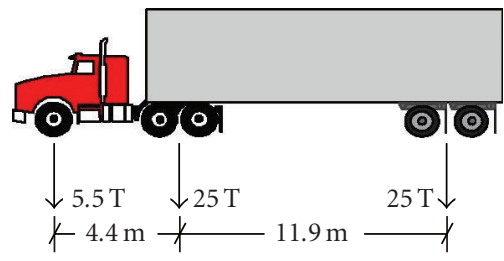

(a)

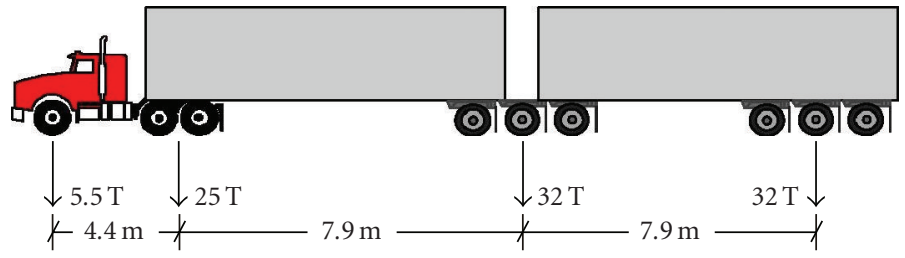

(b)

Figure 15: Description of truck configurations: (a) PV1 five-axle trailer (55.5 T), and (b) PV4 nine-axle trailer (94.5 T).

TABLE 4: Reliability of 1st mode shape from harmonic loading with superimposed noise.

\begin{tabular}{|c|c|c|c|c|c|}
\hline \multirow{2}{*}{ Source of noise } & \multirow{2}{*}{ Reference mode shape } & \multicolumn{4}{|c|}{ MAC value at varying noise levels } \\
\hline & & No noise & $1 \%$ noise & $5 \%$ noise & $10 \%$ noise \\
\hline \multirow{2}{*}{ Input (force) } & Eigenvalue & 0.99498 & 0.99497 & 0.99522 & 0.99523 \\
\hline & Time domain (no noise) & 1.00000 & 1.00000 & 1.00000 & 1.00000 \\
\hline \multirow{2}{*}{ Output (response) } & Eigenvalue & 0.99498 & 0.99540 & 0.99550 & 0.99490 \\
\hline & Time domain (no noise) & 1.00000 & 1.00000 & 1.00000 & 1.00000 \\
\hline
\end{tabular}


TABLE 5: Natural frequencies generated using random forced excitation.

\begin{tabular}{|c|c|c|c|c|c|c|c|}
\hline \multirow{3}{*}{ Mode } & \multicolumn{7}{|c|}{ Natural frequencies $(\mathrm{Hz})$} \\
\hline & \multirow{2}{*}{ Eigenvalue analysis } & \multicolumn{3}{|c|}{ Random-Forced vibration phase } & \multicolumn{3}{|c|}{ Random-free vibration phase } \\
\hline & & Avg. & $\sigma$ & Error $(\%)$ & Avg. & $\sigma$ & Error $(\%)$ \\
\hline 1 & 2.480 & 2.477 & 0.047 & 0.12 & 2.479 & $1.542 \mathrm{E}-07$ & 0.04 \\
\hline 2 & 4.024 & 4.050 & 0.072 & -0.65 & 4.019 & $1.488 \mathrm{E}-06$ & 0.12 \\
\hline 3 & 5.695 & 5.600 & 0.117 & 1.67 & 5.680 & $1.696 \mathrm{E}-06$ & 0.26 \\
\hline
\end{tabular}

TABLE 6: MAC values for mode shapes generated using random forced excitation.

\begin{tabular}{lccccccc}
\hline Excitation phase & \multicolumn{9}{c}{ Mode } & & 5 & 6 & 7 \\
& 1 & 2 & 3 & 4 & 0.9338 & 0.0161 & 0.7632 \\
Forced vibration & 0.9957 & 0.6142 & 0.3244 & 1.0000 & 1.0000 & 1.0000 \\
Free vibration & 0.9957 & 1.0000 & 1.0000 & 1.0000 \\
\hline
\end{tabular}

TABLE 7: Natural frequencies and mode shapes derived from impact loading.

\begin{tabular}{lcccc}
\hline \multirow{2}{*}{ Mode } & \multicolumn{3}{c}{ Natural frequency } & \multirow{2}{*}{ MAC values } \\
& Eigenvalue $(\mathrm{Hz})$ & Impact $(\mathrm{Hz})$ & Error (\%) & \\
\hline 1 & 2.480 & 2.472 & 0.32 & 0.9957 \\
2 & 4.024 & 4.006 & 0.45 & 0.9902 \\
3 & 5.695 & 5.609 & 1.51 & 0.6270 \\
\hline
\end{tabular}

considered here. A typical acceleration response spectrum for simulated impact loading is presented in Figure 14(b).

As demonstrated in Table 7, the modal properties extracted from the impact loading response were found to be in good agreement with the eigenvalue results. While errors in the natural frequencies, relative to calculated eigenvalues, were comparable to results derived from the forced vibration phase using random loading (Table 5), mode shape MAC values for the lowest two modes were closer to those obtained based on free vibration following the random loading (Table 6). Results for the third mode were less accurate, though, having an unacceptably low MAC value of 0.627 for the 3rd mode shape.

The effect of measurement uncertainty (output noise) on the reliability of extracted modal properties when using impact excitation is summarized in Table 8. It is evident that neither the natural frequency nor mode shape estimates for the fundamental mode were adversely affected to a significant degree by the presence of simulated measurement uncertainty for noise up to the 5\% level. The higher modes, on the other hand, seem much more sensitive to measurement noise, with the accuracy of extracted natural frequencies and mode shapes generally deteriorating with increasing levels of noise. In fact, the second mode could not be detected in the presence of $5 \%$ measurement noise. One curious, and unexplained, anomaly was observed in the mode shape estimates for the third mode, for which the MAC value actually increased with an increase in the level of measurement noise from $2 \%$ to $5 \%$, although the natural frequency estimate continued to degrade.
5.4. Truck Loading Excitation. Truck loading effects were simulated by moving a set of vertical forces, configured to resemble the wheel loads from specific truck types, across the bridge along a straight path at a constant speed. As illustrated in Figure 15, two special permit truck types that had previously been used to check the design capacity of the Red Deer River Bridge were considered in this study: a five-axle trailer (denoted here as PV1) and a nine-axle trailer (denoted here as PV4) with gross weights of $55.5 \mathrm{~T}$ and 94.5 T, respectively [41]. The simulated trucks were "driven" across the bridge at speeds of $15 \mathrm{~m} / \mathrm{s}(54 \mathrm{~km} / \mathrm{h})$ and $22.5 \mathrm{~m} / \mathrm{s}$ $(81 \mathrm{~km} / \mathrm{h})$, travelling in a north-to-south direction.

Two truck loading models were investigated. In the simplified truck model, the wheel loads were treated in a quasistatic manner in which the positions of the loads were adjusted with time but their magnitudes remained constant. At every time step in the analysis, each wheel load was distributed to two nodes adjacent to the wheel along its longitudinal path, based on the relative distance between the two nodes and the current position of the wheel. For the dynamic truck loading model, wheel contact force variations due to vertical motion of the truck were simulated by superimposing sinusoidal oscillations upon the simplified loading histories described above. As suggested by Chan and O'Conner [50], the dynamic component of each wheel load was conservatively imposed at the fundamental natural frequency of the bridge with a magnitude equal to $10 \%$ of the static axle load such that the oscillations at each axle location were perfectly in-phase.

As an example of the simplified loading model, Figure 16(a) describes a typical force-time history at a selected node on the bridge model for the case of a five-axle trailer travelling at $54 \mathrm{~km} / \mathrm{hr}$. The corresponding acceleration time history and spectrum are shown in Figure 16(b) and Figure $17(\mathrm{a})$, respectively, for the same node. Similarities with the measured truck-induced response (Figure 4) are apparent, although the time lag between responses to individual axle loads is greater for this simulated load case due to the lower vehicle speed. In addition, there is a notable absence of the high frequency fluctuations characteristic of the measured data since only seven modes were included 
TABLE 8: Uncertainty in modal properties using impact excitation with noise in output.

\begin{tabular}{|c|c|c|c|c|c|c|c|c|c|}
\hline \multirow{3}{*}{ Analysis description } & \multicolumn{6}{|c|}{ Natural frequency $(\mathrm{Hz})$} & \multicolumn{3}{|c|}{ Mode shape MAC value } \\
\hline & \multicolumn{2}{|c|}{ Mode 1} & \multicolumn{2}{|c|}{ Mode 2} & \multicolumn{2}{|c|}{ Mode 3} & \multirow[b]{2}{*}{ Mode 1} & \multirow[b]{2}{*}{ Mode 2} & \multirow[b]{2}{*}{ Mode 3} \\
\hline & Avg. & $\sigma$ & Avg. & $\sigma$ & Avg. & $\sigma$ & & & \\
\hline Eigenvalue & 2.480 & - & 4.024 & - & 5.695 & - & & & \\
\hline No noise & 2.472 & - & 4.006 & - & 5.609 & - & 0.9957 & 0.9986 & 0.9569 \\
\hline $1 \%$ noise & 2.483 & 0.012 & 4.153 & 0.162 & 5.668 & 0.109 & 0.9956 & 0.489 & 0.5202 \\
\hline $2 \%$ noise & 2.479 & 0.019 & 4.130 & 0.192 & 5.754 & 0.118 & 0.9955 & 0.0319 & 0.4387 \\
\hline $5 \%$ noise & 2.491 & 0.016 & - & - & 6.140 & 0.280 & 0.9955 & - & 0.9787 \\
\hline
\end{tabular}

TABLE 9: Natural frequencies and mode shape MAC values from simplified truck excitation.

\begin{tabular}{lccccc}
\hline Analysis case & \multicolumn{3}{c}{ Natural frequency $[\mathrm{Hz}]$} & \multicolumn{2}{c}{ Mode shape MAC values } \\
& Mode 1 & Mode 2 & Mode 3 & Mode 1 & - \\
Eigenvalue & 2.480 & 4.024 & 5.695 & - & - \\
PV1 $(54 \mathrm{~km} / \mathrm{h})$ & 2.483 & 3.719 & 5.704 & 0.9948 & 0.996 \\
PV1 $(81 \mathrm{~km} / \mathrm{h})$ & 2.319 & 3.810 & 5.342 & 0.98 & 0.9446 \\
PV4 $(54 \mathrm{~km} / \mathrm{h})$ & 2.105 & 3.302 & 5.498 & 0.9754 & 0.5457 \\
PV4 $(81 \mathrm{~km} / \mathrm{h})$ & 2.511 & 3.672 & 5.417 & 0.994 & 0.745 \\
\hline
\end{tabular}

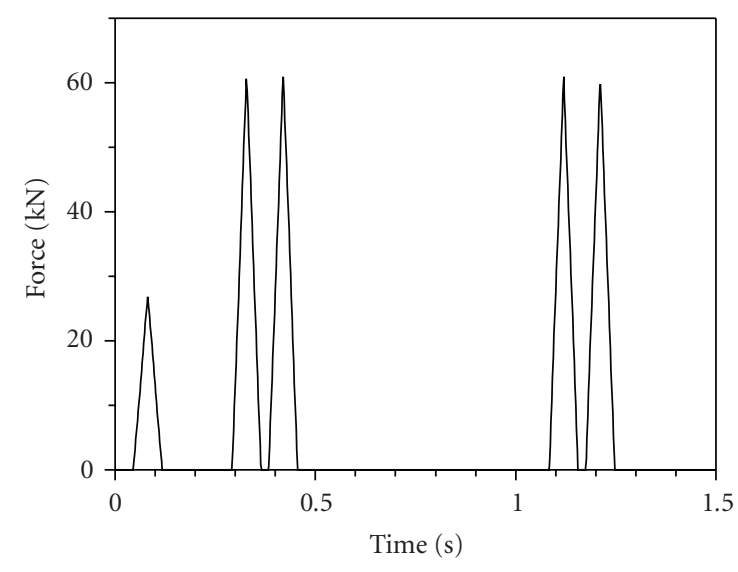

(a)

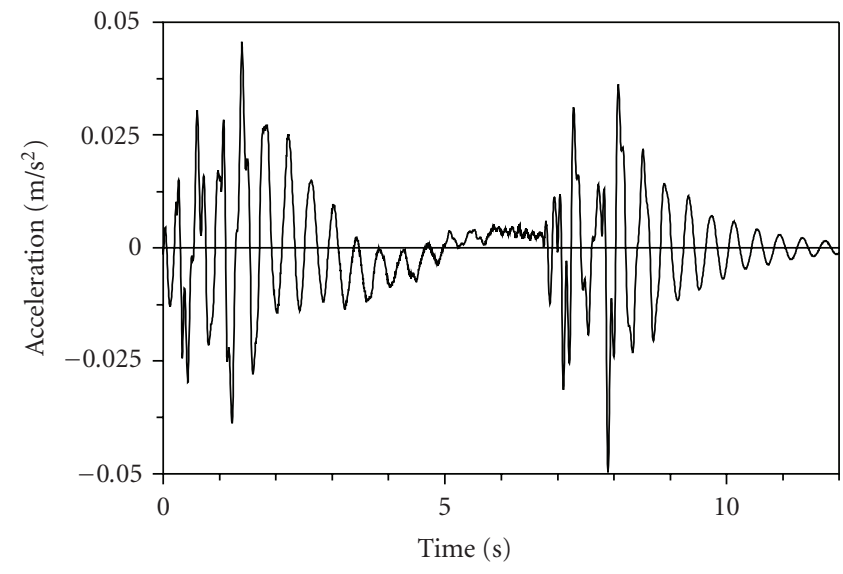

(b)

FIGURE 16: Simplified truck loading model: (a) example nodal loading time history, and (b) corresponding acceleration time history.

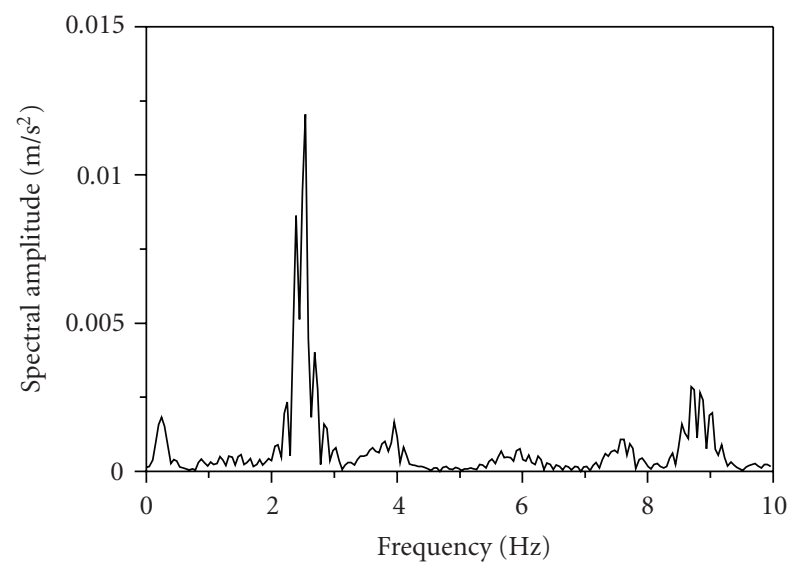

(a)

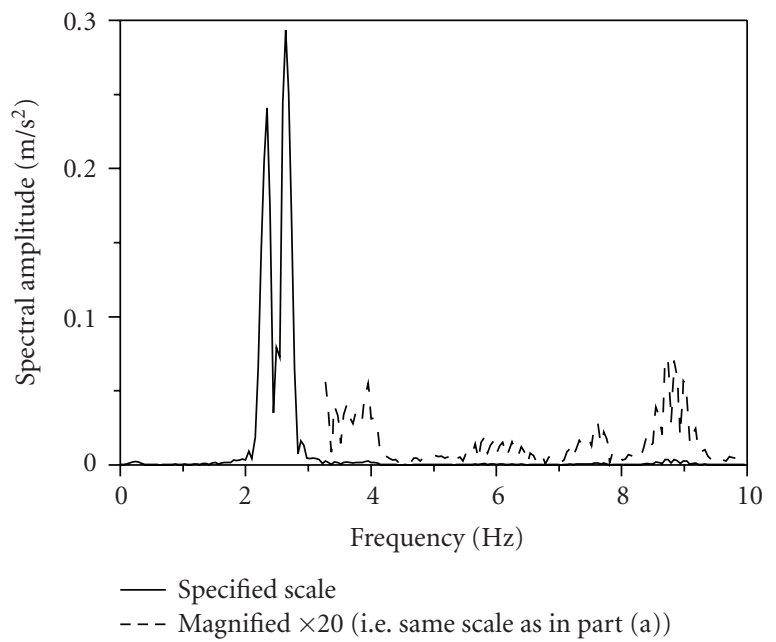

(b)

FIGURE 17: Typical acceleration spectra for simulated truck loading: (a) simplified truck loading model, and (b) oscillating truck loading model. 
TABLE 10: Natural frequencies and mode shape MAC values from dynamic truck excitation.

\begin{tabular}{|c|c|c|c|c|c|c|}
\hline \multirow{2}{*}{ Analysis case } & \multicolumn{3}{|c|}{ Natural frequency $(\mathrm{Hz})$} & \multicolumn{3}{|c|}{ Mode shape MAC values } \\
\hline & Mode 1 & Mode 2 & Mode 3 & Mode 1 & Mode 2 & Mode 3 \\
\hline Eigenvalue & 2.480 & 4.024 & 5.695 & - & - & - \\
\hline PV1 (54 km/h) & 2.307 & - & - & 0.9944 & - & - \\
\hline PV1 (81 km/h) & 2.529 & - & - & 0.9913 & - & - \\
\hline PV4 (54 km/h) & 2.311 & - & - & 0.9942 & - & - \\
\hline PV4 $(81 \mathrm{~km} / \mathrm{h})$ & 2.389 & - & 6.248 & 0.9916 & - & 0.8739 \\
\hline
\end{tabular}

and simulated measurement noise was not considered in this case.

A summary of the lowest three natural frequencies extracted from the forced vibration phase of specified simplified truck-induced excitation cases, along with MAC values for the corresponding mode shapes relative to the eigenvalue solution, are presented in Table 9. In general, the reliability of the modal properties extracted from the truckinduced response was comparable to (or lower than) those based on the forced vibration phase of random loading, and significantly worse than those derived from other excitation sources.

Natural frequencies based on truck loading were found to differ from the eigenvalue results by $0.12-15.1 \%, 5.3-17.9 \%$, and $0.16-4.9 \%$ for the 1 st, 2 nd, and 3 rd modes, respectively, depending on the truck loading case considered. Similarly, mode shape MAC values as low as $0.975,0.546$, and 0.738 were obtained for the fundamental, 2nd, and 3rd modes, respectively. A possible explanation for the poor results was proposed by Chen et al. [34], who noted that spatial correlation effects associated with moving vehicle loads may impair the effectiveness of conventional output-only system identification procedures, such as the SSI method, that are based on the assumption of uncorrelated white noise excitation.

These same truck loading cases were reanalysed using the dynamic truck loading model, with the results summarised in Table 10. Comparing Table 10 with Table 9, it is immediately obvious that the inclusion of temporal oscillations in the axial loads significantly degraded the reliability of extracted properties for the higher modes. Consistent with observations from the field testing program (Section 3.2 ), identification of these modes failed completely for some loading events under this form of excitation. Again, this may be partly attributed to the form of the dynamic excitation, which may not have been suitable for the system identification methods used here. At the same time, however, parameter estimation for the fundamental mode actually improved relative to the simplified truck loading approach, with the average relative error in the natural frequency decreasing from $5.7 \%$ to $4.9 \%$ and the average mode shape MAC value increasing from 0.986 to 0.993 when the forcing oscillations at the 1st natural frequency were added. Although this result was predetermined, in a sense, by the choice of forcing frequency in the dynamic truck loading model, it does highlight the sensitivity of outputonly modal analysis to the frequency content of the dynamic excitation.
As can be expected, the addition of simulated measurement noise to the extracted response time histories caused a further deterioration in the accuracy of estimated modal properties. This was true to approximately the same degree for both the simplified and complex truck loading model results.

\section{Summary and Conclusions}

The influence of the dynamic excitation source on modal parameter estimation for a three-span reinforced concrete bridge was investigated experimentally and numerically in this study. In addition to controlled and unregulated truck loading, dynamic excitation from harmonic, random and impact forced loading, as well as from naturally occurring environmental sources were considered.

Field measurements of truck-induced vibrations demonstrated that modal parameters estimated on the basis of the free vibration response after the truck had left the bridge were significantly more reliable than those derived from the forced vibration phase when the truck was present. In most cases, it was difficult or impossible to generate reproducible mode shapes from forced vibration data, highlighting the strong influence exerted by loading characteristics on modal parameter identification based on short-duration transient excitation events. In contrast, free vibration records associated with 14 timber truck loading events produced very consistent results, with coefficients of variation calculated for the lowest three measured natural frequencies of less than $0.7 \%$, and fundamental mode shape amplitudes at 12 locations on the deck of the central bridge span having coefficients of variation averaging approximately 4\%. Significant uncertainty was also found in modal parameter estimates derived from wind- and water-induced vibrations, although averaging spectral results over multiple data segments was seen to attenuate this uncertainty. In the present study, though, the recorded duration of such ambient vibration events (less than two minutes in most cases) was found to be insufficient to enable reliable modal parameter estimation.

Numerical results from a calibrated finite element model were used to supplement the experimental data. Harmonic forced loading at the fundamental natural frequency was found to produce reliable and robust estimates of the first vibration mode shape, even in the presence of high levels of "white noise" superimposed on either the forcing (input) or response (output) time histories. Due to the proximity of the second and third natural frequencies, however, resonant harmonic loading at those frequencies produced operational 
deflected shapes that differed significantly from the desired pure mode shapes.

To study random loading, the model was subjected to multiple loading events consisting of a simulated 10 second period of broad-band forcing, followed by a 5 second free vibration phase. The free vibration data was found to generate more reliable estimates of the lowest three natural frequencies, both in terms of absolute accuracy and levels of uncertainty, as well as much higher quality mode shape definitions for higher modes. Extracted modal properties based on calculated responses to simulated impact loading were of comparable quality to the free vibration results from the random forcing study, at least for the lowest two modes.

Two simulated truck loading models were investigated; a quasistatic approach in which the axle loads were simply moved across the bridge at a constant speed, and a "dynamic" model in which a harmonic loading component, acting at the fundamental natural frequency of the bridge, was superimposed on the quasistatic load history. Modal parameter extraction results for the truck loading were seen to be comparable in quality to those taken from the forced vibration phase of the random loading study, and significantly worse than for other loading types. In this sense, the numerical results corroborated findings from the field study showing free vibration results to be superior to those obtained from forced vehicle-induced vibration.

\section{Acknowledgments}

The financial support of the ISIS Canada Network of Centres of Excellence and Saskatchewan Highways and Transportation for this work is gratefully acknowledged. The contributions of Mr. D. Pavier and Mr. Brennan Pokoyoway to the experimental aspects of this work are also greatly appreciated.

\section{References}

[1] S. W. Doebling, C. R. Farrar, M. B. Prime, and D. W. Shevitz, "Damage identification and health monitoring of structural and mechanical systems from changes in their vibration characteristics: a literature review," Tech. Rep. LA 13070-MS, Los Alamos National Laboratory, Los Alamos, NM, USA, 1996.

[2] S. W. Doebling, C. R. Farrar, and M. B. Prime, "A summary review of vibration-based damage identification methods," Shock and Vibration Digest, vol. 30, no. 2, pp. 91-105, 1998.

[3] H. Sohn, C. R. Farrar, F. M. Hemez, D. D. Shunk, D. W. Stinemates, and B. R. Nadler, "A review of structural health monitoring literature: 1996-2001,” Tech. Rep. LA-13976-MS, Los Alamos National Laboratory, Los Alamos, NM, USA, 2003.

[4] P. Cawley and R. D. Adams, "The location of defects in structures from measurements of natural frequencies," Journal of Strain Analysis, vol. 14, no. 2, pp. 49-57, 1979.

[5] O. S. Salawu, "Detection of structural damage through changes in frequency: a review," Engineering Structures, vol. 19, no. 9, pp. 718-723, 1997.

[6] B. Peeters, System identification and damage detection in civil engineering, Ph.D. thesis, Department of Civil Engineering, Katholieke Universiteit Leuven, Leuven, Belgium, 2000.
[7] C. H. J. Fox, "The location of defects in structures: a comparison of the use of natural frequency and mode shape data," in Proceedings of the 10th International Modal Analysis Conference, pp. 522-528, Society of Experimental Mechanics, Bethel, Conn, USA, 1992.

[8] O. S. Salawu and C. Williams, "Damage location using vibration mode shapes," in Proceedings of the 12th International Modal Analysis Conference, pp. 933-939, Society of Experimental Mechanics, Bethel, Conn, USA, 1994.

[9] A. K. Pandey, M. Biswas, and M. M. Samman, "Damage detection from changes in curvature mode shapes," Journal of Sound and Vibration, vol. 145, no. 2, pp. 321-332, 1991.

[10] Z. Zhang and A. E. Aktan, "The damage indices for constructed facilities," in Proceedings of the 13th International Modal Analysis Conference, pp. 1520-1529, Society of Experimental Mechanics, Bethel, Conn, USA, 1995.

[11] A. K. Pandey and M. Biswas, "Damage detection in structures using changes in flexibility," Journal of Sound and Vibration, vol. 169, no. 1, pp. 3-17, 1994.

[12] D. C. Zimmerman and M. Kaouk, "Structural damage detection using a minimum rank update theory," Journal of Vibration and Acoustics, vol. 116, no. 2, pp. 222-231, 1994.

[13] J.-T. Kim and N. Stubbs, "Model-uncertainty impact and damage-detection accuracy in plate girder," Journal of Structural Engineering, vol. 121, no. 10, pp. 1409-1417, 1995.

[14] J.-T. Kim and N. Stubbs, "Nondestructive crack detection algorithm for full-scale bridges," Journal of Structural Engineering, vol. 129, no. 10, pp. 1358-1366, 2003.

[15] P. Hajela and F. J. Soeiro, "Recent developments in damage detection based on system identification methods," Structural Optimization, vol. 2, no. 1, pp. 1-10, 1990.

[16] J. R. Casas and A. C. Aparicio, "Structural damage identification from dynamic-test data," Journal of Structural Engineering, vol. 120, no. 8, pp. 2437-2450, 1994.

[17] D. J. Ewins, Modal Testing: Theory, Practice and Application, Research Studies Press, Hertfordshire, UK, 2nd edition, 2000.

[18] C. R. Farrar, P. J. Cornwell, S. W. Doebling, and M. B. Prime, "Structural health monitoring studies of the Alamosa Canyon and I-40 Bridges," Tech. Rep. LA-13635-MS, Los Alamos National Laboratory, Los Alamos, NM, USA, 2000.

[19] B. Peeters, J. Maeck, and G. De Roeck, "Vibration-based damage detection in civil engineering: excitation sources and temperature effects," Smart Materials and Structures, vol. 10, no. 3, pp. 518-527, 2001.

[20] M. F. Green and D. Cebon, "Dynamic response of highway bridges to heavy vehicle loads: theory and experimental validation," Journal of Sound and Vibration, vol. 170, no. 1, pp. 51-78, 1994.

[21] C. E. Ventura, A. J. Felber, and S. F. Stiemer, "Determination of the dynamic characteristics of the Colquitz River Bridge by full-scale testing," Canadian Journal of Civil Engineering, vol. 23, no. 2, pp. 536-548, 1996.

[22] W. Krebs and R. Cantieni, "Analysis of dynamic wheel load signals in the frequency domain," International Journal of Vehicle Design, vol. 6, no. 1, pp. 287-309, 1999.

[23] B. Peeters and G. De Roeck, "Stochastic system identification for operational modal analysis: a review," Journal of Dynamic Systems, Measurement and Control, vol. 123, no. 4, pp. 659667, 2001.

[24] K. P. Jackson, Reliability-based load management of the Red Deer River Bridge, M.S. thesis, University of Saskatchewan, 2007. 
[25] J. R. Billing, "Dynamic loading and testing of bridges in Ontario," Canadian Journal of Civil Engineering, vol. 11, no. 4, pp. 833-843, 1984.

[26] B. Bakht and S. G. Pinjarkar, "Review of dynamic testing of highway bridges," Structural Research Report SRR-89-01, Ministry of Transportation of Ontario, Downsview, Canada, 1989.

[27] J. L. Humar and A. M. Kashif, "Dynamic response of bridges under travelling loads," Canadian Journal of Civil Engineering, vol. 20, pp. 287-298, 1993.

[28] P. Paultre, O. Chaallal, and J. Proulx, "Bridge dynamics and dynamic amplification factors-a review of analytical and experimental findings," Canadian Journal of Civil Engineering, vol. 19, pp. 260-278, 1992.

[29] P. Paultre, J. Proulx, and M. Talbot, "Dynamic testing procedures for highway bridges using traffic loads," Journal of Structural Engineering, vol. 121, no. 2, pp. 362-376, 1995.

[30] A. V. Pesterev, L. A. Bergman, and C. A. Tan, "A novel approach to the calculation of pothole-induced contact forces in MDOF vehicle models," Journal of Sound and Vibration, vol. 275, no. 1-2, pp. 127-149, 2004.

[31] T.-C. Pan and J. Li, "Dynamic vehicle element method for transient response of coupled vehicle-structure systems," Journal of Structural Engineering, vol. 128, no. 2, pp. 214-223, 2002.

[32] T.-L. Wang, D. Huang, M. Shahawy, and K. Huang, "Dynamic response of highway girder bridges," Computers and Structures, vol. 60, no. 6, pp. 1021-1027, 1996.

[33] R. J. Jiang, F. T. K. Au, and Y. K. Cheung, "Identification of vehicles moving on continuous bridges with rough surface," Journal of Sound and Vibration, vol. 274, no. 3-5, pp. 10451063, 2004.

[34] Y. Chen, M. Q. Feng, and C.-A. Tan, "Modeling of traffic excitation for system identification of bridge structures," Computer-Aided Civil and Infrastructure Engineering, vol. 21, no. 1, pp. 57-66, 2006.

[35] A. Pavic, R. Pimentel, and P. Waldron, "Instrumented sledge hammer impact excitation: worked examples," in Proceedings of IMAC-XVI, pp. 929-935, Kissimmee, Fla, USA, 1997.

[36] M. W. Trethewey and J. A. Cafeo, "Tutorial: signal processing aspects of structural impact testing," The International Journal of Analytical and Experimental Modal Analysis, vol. 7, no. 2, pp. 129-149, 1992.

[37] ISO, "ISO Standard 7626-5: Vibration and ShockExperimental Determination of Mechanical Mobility-Part 5: Measurements using impact excitation with an exciter which is not attached to the structure," International Organization for Standardization, Geneva, Switzerland, 1994.

[38] C. R. Farrar, T. A. Duffey, P. J. Cornwell, and S. W. Doebling, "Excitation methods for bridge structures," in Proceedings of the 17th International Modal Analysis Conference (IMAC '99), pp. 1063-1068, Kissimmee, Fla, USA, 1999.

[39] Z. Zhang, "Error study of bridge tests for the purpose of structure identification," in Proceedings of the 12th International Modal Analysis Conference (IMAC '94), pp. 433-441, Honolulu, Hawaii,USA, 1994.

[40] J. M. W. Brownjohn, P. Moyo, P. Omenzetter, and Y. Lu, "Assessment of highway bridge upgrading by dynamic testing and finite-element model updating," Journal of Bridge Engineering, vol. 8, no. 3, pp. 162-172, 2003.

[41] Earth Tech, "Strengthening project of Red Deer River Bridge on Provincial Highway," Tech. Rep. 9, Saskatchewan Highways and Transportation, Earth Tech, Saskatoon, Canada, 2001.
[42] L. Hermans and H. van der Auweraer, "Modal testing and analysis of structures under operational conditions: industrial applications," Mechanical Systems and Signal Processing, vol. 13, no. 2, pp. 193-216, 1999.

[43] S. D. Stearns and R. A. David, Signal Processing Algorithms in MATLAB, Prentice-Hall, Upper Saddle River, NJ, USA, 1996.

[44] C. Y. Shih, Y. G. Tsuei, R. J. Allemang, and D. L. Brown, "Complex mode indication function and its applications to spatial domain parameter estimation," Mechanical Systems and Signal Processing, vol. 2, no. 4, pp. 367-377, 1988.

[45] A. B. Siddique, B. F. Sparling, and L. D. Wegner, "Assessment of vibration-based damage detection for an integral abutment bridge," Canadian Journal of Civil Engineering, vol. 34, no. 3, pp. 438-452, 2007.

[46] ANSYS, ANSYS Release 9.0., ANSYS, Canonsburg, Pa, USA, 2005.

[47] R. W. Clough and J. Penzien, Dynamics of Structures, McGrawHill, New York, NY, USA, 2nd edition, 1975.

[48] A. K. Chopra, Dynamics of Structures: Theory and Applications to Earthquake Engineering, Prentice-Hall, Upper Saddle River, NJ, USA, 1995.

[49] B. Van den Branden, B. Peeters, and G. De Roeck, "Introduction to MACEC 2, modal analysis on civil engineering constructions," Department of Civil Engineering, Katholieke Universiteit, Leuven, Belgium, 1999.

[50] T. H. T. Chan and C. O'Conner, "Vehicle model for highway bridge impact," Journal of Structural Engineering, vol. 116, pp. 1772-1791, 1990. 

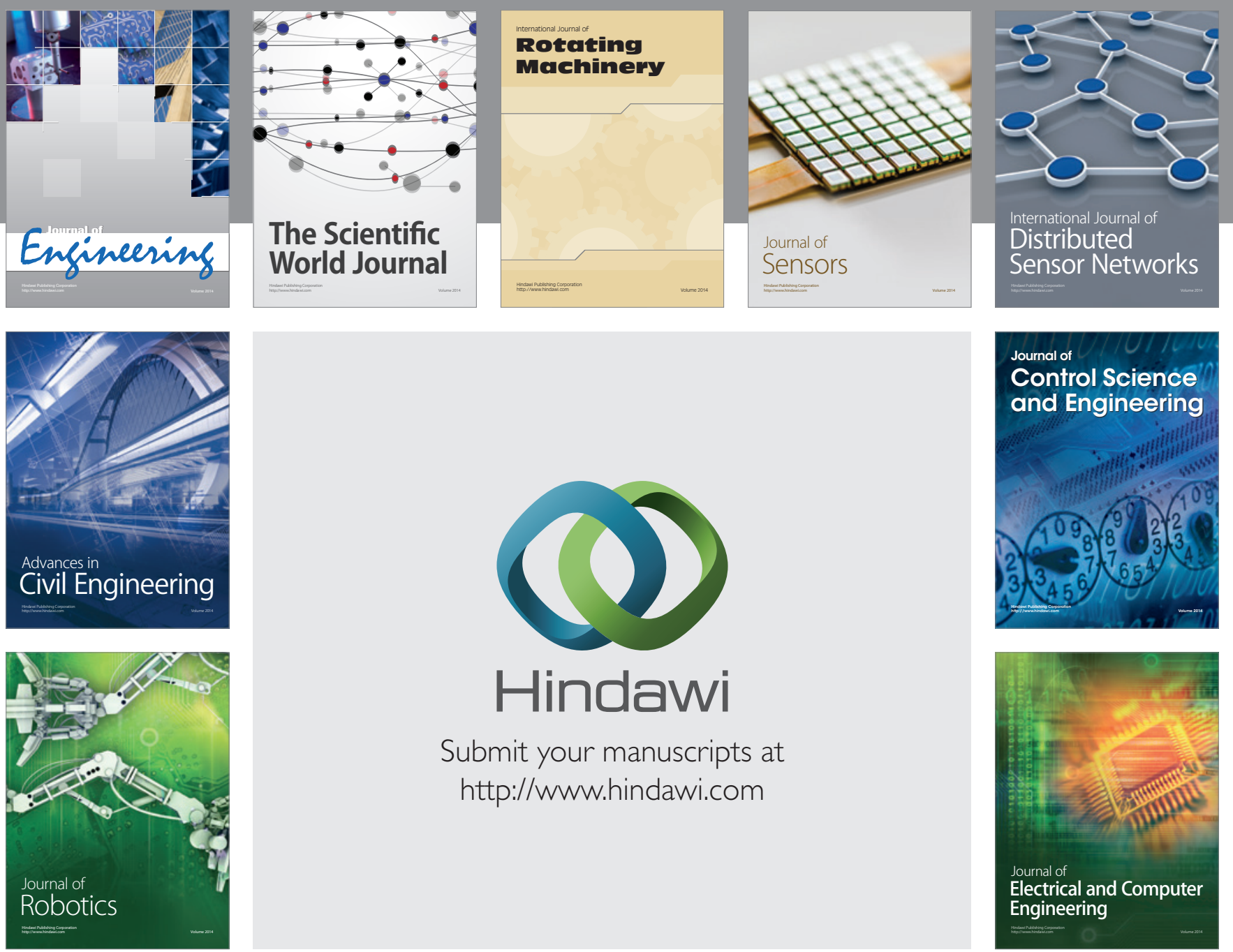

Submit your manuscripts at

http://www.hindawi.com
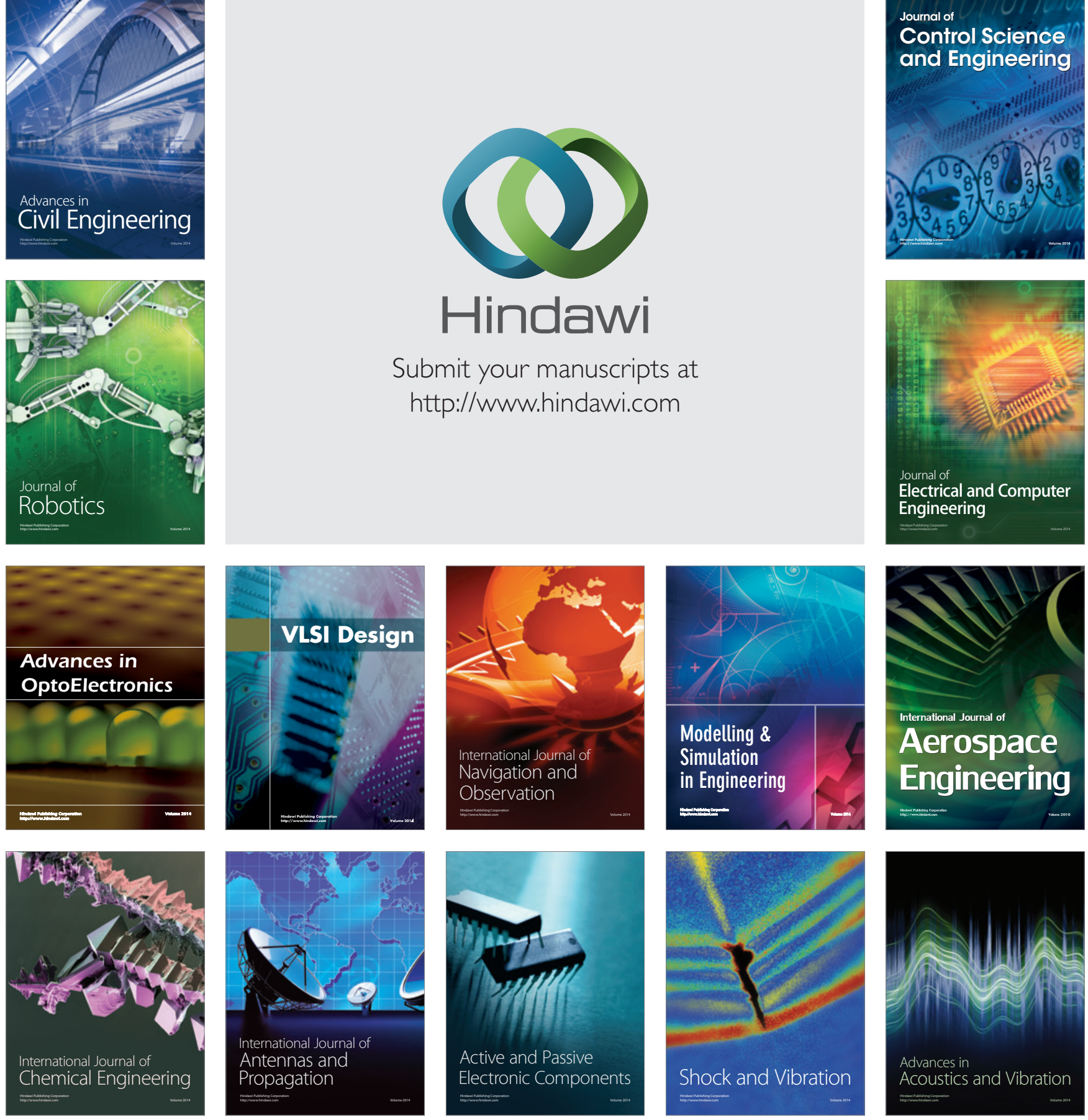